\title{
UPLC-MS Metabonomics Reveals Perturbed Metabolites in HIV-Infected Sera
}

\author{
Aurelia Williams ${ }^{1}$, Khanyisile Kgoadi ${ }^{1}$, Francois Steffens ${ }^{2}$, Paul Steenkamp ${ }^{3}$, Debra Meyer ${ }^{1}$. \\ ${ }^{1}$ Biochemistry Department, University of Pretoria, Pretoria 0002, South Africa \\ ${ }^{2}$ Department of Statistics, University of Pretoria, Pretoria 0002, South Africa \\ ${ }_{3}^{3}$ Natural Products Research Group, Biosciences Unit, CSIR, Pretoria 001, South Africa \\ *Address correspondence to this author at the Biochemistry Department, University of Pretoria, Pretoria 0002, South Africa
}

Tel: +27 12420 2300; Fax: +27 12362 5302; Email: debra.meyer@up.ac.za

\begin{abstract}
Immune responses to infection by the human immunodeficiency virus (HIV) and the use of highly active antiretroviral therapy (HAART) to treat HIV infection, contributes to metabolic irregularities in the host. Current methods for the extraction and identification of metabolites in biofluids generally make use of laborious, time-consuming protocols. Here, 96-well Ostro ${ }^{\mathrm{TM}}$ plates and filtration under positive pressure was used to facilitate the simultaneous, reproducible extraction of metabolites from multiple serum samples which were then analyzed by ultra-performance liquid chromatography mass spectrometry (UPLC-MS). The easy to use solid phase extraction (SPE) protocol eliminated numerous potential contaminants while the UPLC-MS detection of metabolites produced visibly different chromatograms for HIV negative $(n=16), H I V+(n=13)$ and HIV+HAART+ $(n=15)$ serum samples. Linear discriminant analysis (LDA) amplified these differences, classified the groups with $100 \%$ accuracy and identified biomarkers explaining the greatest variances between the groups. The 21 metabolites altered by HIV and/or HAART primarily represented those linked to lipid and energy pathways which is where known metabolic changes associated with HIV infection occur. This work demonstrated for the first time that Ostro ${ }^{\mathrm{TM}}$ plates and UPLC-MS metabonomics was able to successfully identify distinct differences between the experimental groups and detected metabolites related to HAART and other drugs used in the treatment of HIV-associated conditions. The findings of this approach suggests a possible role for this methodology in disease prognosis as well as in the monitoring of treatment success or failure and linking treatment to metabolic complications.
\end{abstract}

Keywords: Biofluid $\bullet$ Biomarker $\bullet \mathrm{HAART} \bullet \mathrm{HIV} \bullet \mathrm{LDA} \bullet$ Metabonomics $\bullet$ Ostro $^{\mathrm{TM}}$ plates $\bullet \mathrm{UPLC}-\mathrm{MS}$ 


\section{INTRODUCTION}

During HIV infection, host metabolism is influenced among other things by the virus [1-3], immune responses [4-6] and treatment [7, 8]. HAART, primarily used to restore HIV-induced effects, prolongs the lifespan of infected individuals [8] and has subsequently resulted in HIV infection becoming a chronic condition, especially in developed countries. As a result, there has been an increase in the incidence of chronically infected individuals presenting with HIV and treatement-induced metabolic disturbances. Metabolic dysfunction during HIV infection is not a singular event so much so that a combination of metabolic changes can be induced at one time. This combination of metabolic disorders are routinely defined as metabolic syndrome in the relevant literature where the terminology refers to for example insulin resistance, dyslipidaemia, lipodystrophy, and so on, sometimes occurring in concert [9-11].

Metabolites associated with HIV and/or HAART-induced metabolic disturbances include glucose, other carbohydrates and lipids. Alterations in the metabolism of carbohydrates (e.g glucose, [12]) and lipids [13, 14] have been identified very early in AIDS research as key metabolites affected during HIV infection. These early observations were however, made using laborious conventional rather than metabonomics methodologies [15].

Because metabolites are (i) the end products of all enzymatic/chemical reactions occurring in the body, (ii) altered by infection and treatment, (iii) detectable through analytical techniques and (iv) informative regarding an individual's physiological state [16], these molecules are being revisited for their role as biomarkers of HIV infection (see studies highlighted in [15). To date, accurate and reliable markers for the diagnosis of HIV infection, monitoring of disease progression and assessing the success of therapeutic interventions are still lacking [17]. This is because many molecules that are influenced by HIV infection fail to meet the basic requirements of a biomarker (as defined by Kanekar, 2010 [18] as well as Beger and Colatsky, 2012 [19]). In addition; the mechanisms of HIV infection, the functioning of the metabolic and immune systems as well as the roles of various molecules and cells (such as antibodies, CD4 T cells, etc) during infection, are not fully understood [20] and as such hampers the characterization of biomarkers. CD4 count and viral load are two parameters currently used in the clinic for the prognosis and management of HIV/AIDS but are not always reliable (e.g changes in CD4 count due to other infections, collection time etc.) supporting the need to develop 
new detection methodologies and novel biomarkers for the characterization of HIV infection and treatment success/failure.

Traditional biochemical assays used to measure metabolic changes have the disadvantage of detecting one analyte at a time. Studies measuring several metabolic changes through the use of multiparametric analytical tools such as UPLC-MS and the application of metabonomics methodologies have already demonstrated the advantage of this holistic approach to better understanding the effects of HIV infection [21, 22]. UPLC-MS has numerous advantages over conventional biochemical analysis of metabolites including data collected in relatively short time frames, low sample volumes, large separation efficiencies and most importantly higher resolutions [23-25]. Although analytical instrumentation such as UPLC-MS can detect low molecular weight molecules effeciently, sample preparation for these type of experiments is of extreme importance if accurate clinical information is to be obtained [16]. In previous MS studies where metabolic changes were measured; tedious, time-consuming extraction protocols were used (see Figure 1 and associated references). These protocols comprise several extraction steps which increases the variability of the data, lowering both the validity and the reliability thereof. To minimize these issues, the Metabolomics Standards Initiative (MSI) published guidelines to help standardize metabonomics sample handling, data analysis and data storage protocols [26].

As a contribution to the MSI, in this article, an easy, rapid yet reproducible method for extracting metabolites from HIV-infected sera through the use of Ostro ${ }^{\mathrm{TM}}$ plates for sample analysis in UPLC-MS metabonomics is reported (also outlined in Figure 1). Although Ostro ${ }^{\mathrm{TM}}$ and other 96-well SPE plates, under vacuum filtration, have been applied to non-HIV studies [27-30], biofluid metabonomics experiments [31] as well as to plasma samples to determine the concentration of antiretroviral drugs $[32,33]$, such analysis has not been applied to HIV-infected biofluids for the identification of virus and/or HAART-influenced metabolic differences between groups. Neither has the extraction of metabolites been facilitated through filtration under positive pressure. The advantage of filtration under positive pressure is that it allows for the uniform, reproducible recovery of a diverse group of analytes and an improved flow for viscous samples. Most plate formats incorporate several steps (plate conditioning followed by sample loading and well washing) [28, 32-34 and Figure 1] before the final sample is eluted while Ostro ${ }^{\mathrm{TM}}$ plates use a one step precipitation and extraction process. Sample preparation, handling time and long extraction steps are eliminated which minimize sample degradation, as reported by others [31]. Less sample handling means less variation in the data and less time 
spent on method development. Ostro ${ }^{\mathrm{TM}}$ plate procedures are generally also less destructive to metabolites [30], the plastic used in the manufacture of these plates is inert minimizing leaching of plasticizers. The most novel aspect of these plates are their ability to remove phospholipids from samples. Phospholipids contribute to matrix effects and can accumulate on the chromatographic column ultimately resulting in variable analyte signals. Phospholipids are also known to cause ion suppression during MS analysis, masking analyte detection [35].

The aim of this work was to apply an easy to perform SPE protocol (using Ostro ${ }^{\text {TM }}$ plates) to better prepare serum samples for improved UPLC-MS biofluid metabonomics data collection. It was important to demonstrate that the protocols (for sample extraction and data collection) could be applied to randomly collected serum samples (to show that the method applied was able to detect metabolic changes in any patient irrespective of disease status or other possibly confounding factors like age, lifestyle etc) because metabonomics is ultimately aimed at clinical application. In the data presented here, clear differences were observed between the metabolic profiles of the three study groups prior to the use of statistics. These differences were amplified following multivariate analysis. LDA classified the groups as HIV negative, HIV+ and HIV+HAART+ with $100 \%$ accuracy. The variances between the groups were mainly explained by molecules involved in lipid and energy metabolism as well as metabolites (e.g. nucleotides ) influenced by treatment of the patients. This is the first time, using Ostro $^{\mathrm{TM}}$ plates and a metabonomics approach that the metabolites of drugs used to treat HIVassociated conditions are detected in infected biofluids such as serum.

\section{MATERIALS AND METHODS}

\section{Experimental Design and Sample Preparation}

A global analysis was done on the sera of HIV-seronegative (HIV negative), HIV-seropositive (HIV+) and HIV+ individuals undergoing treatment (HIV+HAART+). Blood samples of HIV negative, HIV+ and HIV+HAART donors $(\mathrm{n}=16,13$ and 15 respectively) were obtained from The Fountain of Hope Clinic in Pretoria as well as the King's Hope Development Foundation and Mooiplaas Clinics in Diepsloot, Johannesburg. Patient samples were selected randomly to test how well the approach would perform in situations where patient visits are not always by appointment. Blood was collected from these study groups following written informed consent. The participating HIV+ donors had not been diagnosed as having AIDS with the exception of two patients who presented with CD4 counts of less than 200 cells $/ \mathrm{mm}^{3}$ after the start of the study. Patients on treatment were also prescribed different HAART combinations. Viral load, measured by 
the COBAS AmpliPrep/COBAS TaqMan HIV-1 Test (Roche Molecular Systems, Pleasanton, CA) was not part of the inclusion criteria because practices at the source clinics were such that the viral load of individuals was determined only when they were tested for HIV infection for the first time and then immediately before treatment was initiated. Healthy control donors were recruited at the Hatfield campus of the University of Pretoria and had no known metabolic or other medical condition at the time of blood collection. The HIV negative status of these samples was confirmed with VISITECT ${ }^{\circledR}$ HIV $1 / 2$ rapid tests (Omega Diagnostics Limited, Scotland, UK). The negative controls and HIV+ samples were fairly well-matched in terms of gender but not age (HIV negative group was younger than HIV+ groups). Detailed demographic information of the participating donors is supplied in Table 1.

Venous blood was collected in non-EDTA vacutainers (Greiner Bio-One GmbH, Kremsmünster). Serum was removed after centrifugation at $1610 \times \mathrm{g}$ for 10 minutes and stored at $-70{ }^{\circ} \mathrm{C}$ until use. The time from venous puncture to storage of the sera was approximately 4 hours.

\section{Chemicals and Solvents}

All chemicals for UPLC-MS experiments were of ultra-pure LC-MS grade. Formic acid was purchased from Fluka (Steinheim, Germany) while acetonitrile was purchased from Romil Ltd (Cambridge, United Kingdom). Ultra-pure water was generated by a Millipore Elix 5 RO system and Millipore Advantage Milli-Q system (Millipore SAS, Molsheim, France).

\section{UPLC-MS Method Development and Optimization}

The first aspect considered was the type of samples to be analyzed. Being blood-derived, one would expect polar to intermediate polarity compounds to be predominantly present in sera. Due to the nature of the samples, a C18 UPLC column served as a good starting point but a C18 column with polar embedded functionality or special end capping could enhance the separation of blood sample extracts. To enhance the possibility of separating all compounds ionized in the source of the mass spectrometer, the maximum column length of $150 \mathrm{~mm}$ was used for all column evaluations. The columns evaluated were the BEH C18 column as well as the T3 C15 column from Waters. Although the BEH C18 column chemistry gave good retention of the more polar compounds, it could not equal the superior retention and resolution observed on the T3 C15 column. The T3 150mm UPLC column was therefore used in all further experimental work. 
The second aspect was to optimize the ionization settings of the mass spectrometer. Quality control (QC) samples which comprised a pool of all samples used in the study [36] or a pool of representative samples from each condition being investigated (e.g. HIV negative, HIV+ and HIV+HAART+; [35]) were prepared. The QC sample was infused into the inlet probe while scanning the TOF analyzer in both ESIPos and ESINeg ionization modes. Mass ions were observed in both modes and resulted in the optimization of both modes in regards to capillary voltage, cone voltage and extractor voltage. The trap voltage was set at $4 \mathrm{~V}$ to ensure that no unnecessary fragmentation would occur during ion transmission. The settings as detailed in the experimental section were found to provide the best ionization of the most compounds in both polarity modes and were used in all experimental work.

The third aspect evaluated was the stability of the method. QC samples were prepared and used to monitor the stability of sample runs during UPLC-MS analysis. A pooled sample was analyzed by doing ten consecutive injections on the same day and repeating the same analysis on the next day and comparing the two data sets. It was found that the UPLC column required three conditioning injections prior to starting the main analysis run. The results for the inter- day and intra-day experiments compared very well and ensured that extended sample runs would be possible even if the whole analysis run would span over several days. To minimize the effect of subtle changes in the separation over long analysis runs, all the samples were randomized in the sample table prior to analysis. Blanks were included to assess carryover and exclude possible contaminating ion features.

\section{Optimized Metabolite Extraction from Sera using Ostro ${ }^{\mathrm{TM}}$ Plates}

Ostro $^{\mathrm{TM}}$ sample preparation plates (Waters Corporation, Milford, USA) and filtration through the Waters positive pressure-96 processor (Waters Corporation, Milford, USA) was utilized to facilitate serum metabolite extraction. Serum samples were thawed on ice prior to extraction to avoid loss of volatiles. Briefly, the Ostro $^{\mathrm{TM}}$ plate was keyed onto a 96-well collection plate. One hundred microliters of sera, blanks and QC samples were randomly loaded onto the Ostro ${ }^{\mathrm{TM}}$ plate in duplicate, with a few exceptions as explained below which subsequently influenced the number of cases analyzed in electrospray ionization positive (ESI+) and negative (ESI-) mode respectively. Three hundred microliters of freshly prepared $1 \%$ formic acid in acetonitrile was forcefully added to the plate wells and mixed through aspiration. The plate assembly containing sample and solvent was filtered under positive pressure at $414 \mathrm{kPa}(60 \mathrm{psi})$. The collected filtrates in the collection plate were transferred on ice to the UPLC-MS facility for subsequent analysis. 
The top-half of the 96-well collection plate was analyzed in ESI+ mode and the bottom half in ESI-

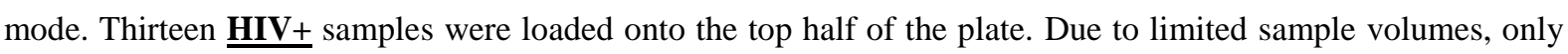
11 cases were duplicated in the lower half of the plate for analysis in ESI- mode. Fifteen $\underline{\text { HIV negative samples }}$ were loaded onto the top half of the plate and duplicated in the bottom half too. Due to insufficient volumes of HIV+ samples, two wells in the bottom half of the plate were vacant and an additional HIV negative sample loaded, in duplicate. The total number of HIV negative samples was therefore 16, with 15 cases analyzed in the

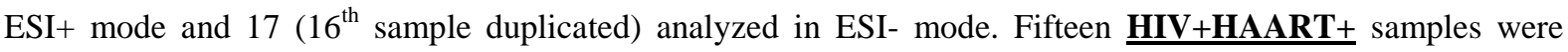
analyzed in ESI+ and ESI- mode respectively. Due to the exclusion of an outlier only 14 HIV+HAART+ cases were considered for further data processing in ESI+ mode.

\section{UPLC-TOF MS Analysis}

All chromatographic and mass spectrometric analysis was performed at the Council for Scientific and Industrial Research (CSIR), Pretoria, South Africa. A Waters Acquity UPLC coupled in tandem to a Waters photodiode array (PDA) detector and a SYNAPT G1 HDMS mass spectrometer was used to generate accurate mass data. Chromatographic separation was done utilizing a Waters HSS T3 column (150 mm x 2.1 mm, 1.8 $\mu \mathrm{m})$ thermostated at $60{ }^{\circ} \mathrm{C}$. A binary solvent mixture was used consisting of water (Eluent A) containing $10 \mathrm{mM}$ formic acid ( $\mathrm{pH} 2.3$ ) and acetonitrile (Eluent B). Gradient elution was performed at a flow rate of $0.4 \mathrm{ml}^{\mathrm{min}} \mathrm{m}^{-1}$. The initial conditions were $95 \%$ of A for 0.1 minute with a gradient profile 7 to $40 \%$ of A at 8 minutes, followed by a gradient profile 5 to $10 \%$ of $\mathrm{A}$ at 14 minutes and kept constant for 1 minute. The system was reequilibrated using the initial conditions with a total runtime of 20 minutes. The injection volume was set at $3 \mu 1$ with triplicate injections acquired per sample. The PDA detector was scanned between 200 and $500 \mathrm{~nm}(1.2 \mathrm{~nm}$ resolution) and collected 20 spectra per second.

The SYNAPT G1 mass spectrometer was used in V-optics and operated in electrospray mode. Leucine enkephalin $(50 \mathrm{pg} / \mathrm{mL})$ was used as reference calibrant to obtain typical mass accuracies between 1 and 3 mDalton. Although positive ionization is commonly used and more compounds are ionized in this state [37], the mass spectrometer was operated in both negative and positive mode of electrospray ionization to enable greater coverage of the metabolome for untargeted analysis. The capillary voltage was set at $2.0 \mathrm{kV}$, the sampling cone at $30 \mathrm{~V}$ and the extraction cone at $4 \mathrm{~V}$. The micro channel plate detector voltage was set at $1950 \mathrm{~V}$. The scan time was 0.1 seconds covering the 100 to 1000 Dalton (Da) mass range. The source temperature was $120{ }^{\circ} \mathrm{C}$ and 
the desolvation temperature set at $450{ }^{\circ} \mathrm{C}$. Nitrogen was used as the nebulization gas at a flow rate of $800 \mathrm{~L} / \mathrm{h}$. MassLynx V4.1 (SCN 704) software was used to control the hyphenated system and for data manipulation.

\section{Data Processing and Statistical Analysis}

Data mining was done by processing the raw ESI- and ESI+ data files with the MarkerLynx Extended Statistics (XS) processing method of the MassLynx software under the following criteria i.e. a retention window of 0.5-17.00 min, a mass range and tolerance of 100-1000 and 0.01 Da respectively. During this time the MarkerLynx XS V4.1, SCN 704 software performed peak integration and alignment as well as background noise subtraction yielding data in a suitable format for statistical analysis.

An additional peak threshold and noise filter was applied to the data within MarkerLynx. The data was exported into Excel® and further analyzed using IBM SPSS (version 19.0). Multivariate statistical analysis in the form of linear discriminant analysis was performed to classify experimental groups and identify metabolites contributing to group variances. LDA is a statistical method that uses a linear combination of variables to maximize between-class variation compared to within-class variation, to bring about an improved separation of experimental groups. Principal component analysis (PCA) was also performed (see supplementary information, Figure S1) but LDA was found to be more appropriate in this case. The method used in the case of PCA was to compute principal components and then to do an LDA on the principal components. This was done because the method is commonly seen in the literature. In the case of LDA based on PCA, all the metabolites ( $\mathrm{n}=1976$ for ESI neg mode and $\mathrm{n}=2511$ for ESI+ mode) are involved in the definition of each principal component. In the case of the LDA based on individual metabolites, stepwise discriminant analysis was used. Eleven and 10 metabolites selected by the stepwise procedure produced a $100 \%$ correct classification for ESI neg and ESI+ modes respectively. The model was not corrected for confounding factors, an aspect addressed under the discussion. The significance of these molecules were also verified through univariate analysis in the form of analysis of variance (ANOVA).

\section{Metabolite Identification}

Mass spectral searches conducted using metabolite and/or structure databases and libraries [BioCyc, ChemSpider, National Institute of Standards and Technology (NIST), Human Metabolome Database (HMDB), Golm, Lipid Maps, Molecular Modeling Database (MMDB), etc] were used to confirm the identities of 
significantly altered metabolites.The molecular formula of the analytes were obtained using MassLynx software. Searches were restricted to $\mathrm{C}, \mathrm{H}, \mathrm{N}, \mathrm{O}, \mathrm{S}$ elementary composition.

\section{Ethics Approval}

Ethics approval for the use of human blood in this research was obtained from the Faculties of Natural and Agricultural Sciences and Health Sciences of the University of Pretoria with protocol numbers EC 08050619 and 163/2008, respectively.

\section{RESULTS}

\section{Experimental Design and Sample Selection}

To study metabolic complications, metabolites are often extracted from affected tissues and biofluids using laborious protocols which incorporate numerous handling steps (Figure 1). As a result, variability is introduced into the data [38]. Utilizing a straightforward, easy to use extraction protocol with minimal handling steps should minimize the chances of obtaining erroneous data. A one-step protein precipitation and extraction protocol is presented here for use in UPLC-MS metabonomics experiments aimed at evaluating HIV and HAART-induced metabolic changes. Metabonomics using Ostro ${ }^{\mathrm{TM}}$ plates and UPLC-MS is also presented to show the unique detection of treatment-associated metabolites in infected biofluid.

The samples used in this study were well-matched in terms of gender and CD4 counts (Table 1). In the case of the treatment-naive HIV+ group, CD4 counts were relatively high and representative of an asymptomatic cohort. The HIV-infected cases were generally older and presented with varying viral loads. The possible influences of these confounding factors are elaborated on in the discussion.

\section{Metabonomic Profiling}

UPLC-MS base peak ion (BPI) chromatograms of HIV negative, HIV+ and HIV+HAART+ sera are shown in Figure 2. Distinct, narrow chromatographic peaks suggest the successful detection of metabolites as well as the removal of phospholipids which previously masked the detection of metabolites when another extraction protocol was followed (see supplementary Figure S2). The chromatograms show the sera of the three groups exhibiting different metabolic profiles, notable by differences in their peak numbers and intensities (Figure 2, also refer to representative circles). It is also evident (Figure 2 [ii] and [iii]) that the metabolism of the uninfected participants and asymptomatic HIV patients are visually more similar and perhaps indicative of the 
health status of the infected patients. The metabolism of the patients receiving HAART was most affected as seen by the increase in the intensitiy of the peaks at 6.65 and 12.95 minutes respectively (Figure 2 [i]).

Following integration and alignment of the MS data, LDA was applied to classify the groups as HIV negative, HIV+ and HIV+HAART+ and also to identify variables accounting for group differences. This statistical tool classified all cases correctly achieving 100\% accuracy (Table 2) pre- and post cross-validation. The number of participants was too small for a full cross-validation by means of a hold-out sample. Instead, the method applied was leave-one-out-at-a-time. Metabonomics data is multivariate and should ideally be analyzed using multivariate statistical approaches to increase the power of the analysis and avoid erroraneous conclusions [39]. ANOVA, applied to determine how well this statistics tool complemented mutlivariate stastics findings, detected many more metabolites that were significantly different between the groups than did LDA. Of the 21 important metabolites identified through LDA, $13(62 \%)$ had p values $<0.05$ (see Table 3 [i] and [ii]) indicating that ANOVA, in terms of the number of significantly altered molecules identified, complimented LDA findings to an extent.

Scatter plots (Figure 3) show maximum between-group separation, suggesting distinct metabolic profiles for each group. The metabolism of the treatment-experienced group was most affected as seen by how far this group is positioned from the HIV negative and HIV+ groups (Figure 3) with the greatest separation achieved along the first discriminant. In Figure 2 there are visual similarities between the metabolism of the HIV negative and HIV+ group which indicate that the infected individuals to still be relatively healthy. This was further amplified in the scatter plots (Figure 3, along the first discriminant). If group separation is evaluated along the second discriminant, it appears that the metabolic profile of the HIV+HAART+ group shifts toward that of the HIV negative group. Within-group metabolic differences were minimal and representative of a homogeneous group of samples. Reliability and validity of the MS runs were also confirmed through the tight clustering of QC samples and tight clustering of technical repeats (finally averaged to allow for LDA).

Following LDA, important variables $(n=21)$ contributing to the clustering of the experimental groups in ESI negative and ESI+ mode were identified (Table 3 [i] and [ii]). Serum contains 90\% water and mainly has polar metabolites [40]. In this study, each ionization mode resulted in the detection of unique metabolites. In the ESI- mode (Table 3 [i]) metabolites involved in lipid and/or membrane biosynthesis as well as nucleotide 
metabolism were mainly identified. Metabolites related to the treatment of HIV-associated conditions as well as amino acid and protein metabolism were mainly identified in ESI+ mode (Table 3[ii]). If the assumption is that the metabolite levels in uninfected sera are normal then the 21 distintinguishing metabolites showed either infection or infection and HAART as being responsible for the shifts/changes in the levels of these molecules (Figure 4).

\section{DISCUSSION}

\section{Experimental Design and Sample Selection}

During random sample selection, the influence of possible confounding factors must be considered, because these factors may account for metabolic differences and influence the clustering of samples. For our dataset; age, gender and the varying viral loads of patients did not appear to be confounding since samples grouped according to these parameters failed to cluster together. When the possible confounder, gender, was included as a variable in the LDA model (see supplementary Figure S3), it did not affect the data. Similarly, when age was applied to the model, it did not play a significant role in the results. In a non-HIV biofluid metabonomics study, Tulipani et al (2013) [31] concluded that solvent extraction in combination with Ostro ${ }^{\mathrm{TM}}$ plates, as also used in our study, allowed for subtle metabolic changes between groups, independent of confounding factors, to be observed. A truly randomized sample set should have included the same age across experimental groups. However, being at the mercy of the volunteer approach, we were limited to using only patients who agreed to involvement and it turns out those younger individuals totally sure of their status only volunteered when negative. As mentioned, the LDA model not responding to gender or age gave the confidence to continue the study. In addition, the fact that infected individuals with differing ages (Table 2, mean age of HIV+ and HIV+HAART groups) separated based on metabolites, strongly supports the validity of the collected data.

\section{Metabonomics Profiling, Perturbed Metabolites and their Biological Significance}

The body largely depends on oxidation processes for its energy supply. This occurs mainly through the breakdown of fats, carbohydrates and amino acids in mitochondria and peroxisomes. HIV, the immune response to infection and treatment disrupts host metabolism. In our findings, treated patients were most differentiated from the HIV negative and HIV+ groups (Figure 2 and Figure 3) suggesting HAART to drastically affect host 
metabolism. The alteration of the host metabolism by the HIV therapeutics is in agreement with the literature [2, 8]. There was also a shift of the HIV+HAART+ group toward the HIV negative group (Figure 3 , along the $2^{\text {nd }}$ discriminant). Whether or not the shift implies successful therapeutic intervention needs to be confirmed by specific analysis. It is important to note that Figure 2 provides representative chromatograms for each experimental group while Figure 3 shows responses of every individual used in the study. The data presented here indicates that HIV and/or HAART interferes mainly with lipid, carbohydrate and therefore energy metabolism which ultimately translates to alterations in cell signalling and other membrane associated reactions. In addition, metabolites associated with the treatment of HIV-associated conditions were also observed. HIVinduced disruption of fatty acid/lipid metabolism which is usually associated with lipodystrophy (fat redistribution) is well-documented in the literature $[8,11-14]$ as is the disruption of carbohydrate and energy metabolism [22, 41-43].

To get a better idea of the contribution of HIV and/or treatment to the measured metabolic alterations, changes in the levels of the respective metabolites were evaluated through mean plots (Figure 4). Of the 21 metabolites identified through LDA as contributing to group differences; $3(14.3 \%)$ were altered due to HIV, $5(23.8 \%)$ were altered due to HAART while $13(61.9 \%)$ were altered as a result of infection and treatment. The plots confirmed infection and treatment to augment metabolic alterations and also reflects the strong influence of HAART on the metabolic profile of the cohort under investigation. Upon reviewing patient records, it was found that of the HAART combinations given to patients, a large percentage of individuals were on combinations of nucleoside reverse transcriptase inhibitors (NRTIs) and non-nucleoside reverse transcriptase inhibitors (NNRTIs, Table 1). These regimens are known for causing mitochondrial dysfunction, lipodystrophy and lactic acidosis [44-46]. HIV-infected cells and lipolysis, which is a common feature of infected individuals, require increased amounts of energy and therefore functional mitochondria for this purpose. Studies have shown early on that HIV-infected cells have higher rates of resting energy expenditure [41, 42] which is in keeping with the high energy demands of infected cells. Mitochondria drive metabolic processes [47] and together with the Krebs cycle serves as the "hub" of cellular metabolism. The human immunodeficiency virus obtains energy mainly by altering host metabolic processes by impacting for example, mitochondria [43]. If compromised, as occurs during HIV infection, energy processes are affected such that adenosine triphosphate (ATP) is depleted and glycolysis activated [48]. This disruption in energy metabolism is evident by the alteration in carbohydrate metabolism detected in our study. Because of the role of this organelle in producing ATP, energy metabolism is 
ultimately affected. Several metabolites, for example, cytidine triphosphate (Table 3 [i]) and 1-Hexadecanoyl-2(9Z-octadecenoyl)-sn-glycerol 3-diphosphate (Table 3 [ii]) were linked to changes in energy metabolism (glycolysis, energy storage and use) in this study. Hollenbaugh et al (2011) [22] too showed an alteration in glycolysis following the in vitro HIV infection of primary CD4 cells and a long-lived macrophage cell line. The increase in glycolysis ultimately results in the increased production of lactic acid, which led to lactic acidosis, another common feature associated with NRTI use [46]. Synonomous with mitochondrial dysfunction, apoptosis inducing factors and proteolytic caspases are released causing cellular damage. Lipolysis is also decreased contributing to the developmnet of lipodystrophy [44]. The use of NRTIs and NNRTIs is thus reflected in our study through changes in lipid, carbohydrate and energy metabolism. The treatment-induced metabolic changes observed here are usually only observed as severe clinical manifestations (very visible/unsightly fat deposits) but was detected here by LC-MS metabonomics in the absence of such clinical changes. This is largely attributed to the sensitiviy of the MS instrument. Detecting these subtle changes not yet be visible to the naked eye, provides supportive reason for further developing metabonomics for disease diagnosis, to monitore drug adherence and for linking specific drug classes to particular metabolic complications. Alterations in fatty acid/lipid metabolism are known to place the affected individuals at risk of cardiovascular diseases making these metabonomics findings highly relevant for the management of HIV/AIDS.

A closer evaluation of the mean plots in Figure 4 could add to our understanding of the mechanisms of HIV and/or HAART-induced metabolic complications. Since most of the metabolic changes involved lipid changes and were as a result of HAART as well as the synergy between infection and treatment, the changes may suggest a mechanism used by the virus to ensure its survival depending on whether the levels of these molecules are increased or decreased. For example, the virus depends on the host's metabolic machinery to survive. It can therefore induce an increase in metabolites involved in lipid and membrane biosynthesis (e.g. V0274MZ213.9635 in Figure 4 [i], identified as Methyl dodecanoate in Table 3 [i]) as well as cell formation ensuring it has a host in which to replicate. Alternatively, the increase in cell turnover may be a host response to infection in order to produce more cells to ward off the virus. A decrease in the levels of this metabolite following the administration of HAART suggests an opposing effect by treatment to restore the level of the metabolite to that of uninfected controls. Whether the shift implies successful therapeutic intervention would require further investigation. Similarly, the remaining plots can be evaluated in this manner but quantitative analysis would be more informative. 


\section{Metabolites Indicative of Treatment}

Of the metabolites detected, there were also indications of changes in nucleotide, amino acid and protein metabolism. Nucleotides serve as the building blocks for deoxyribonucleic acid (DNA) and ribonucleic acid (RNA) synthesis. That nucleotide metabolism is affected in the host is in agreement with the life cycle of the virus i.e. HIV integrating its genetic information into that of the host. Nucleotides serve as energy carriers, cell signalling molecules and cofactors to various reactions. A disruption in the metabolism of these molecules thus adds to the disruption in cell signalling already induced by HIV and/or its treatment. Nucleotide metabolism in the context of HIV infection is important because HIV cannot encode nucleotide-metabolizing enzymes and it's intracellular replication requires a continous supply of deoxynucleotidetriphosphate (dNTPs, [49]).

Proteins serve important biological roles including catalyzing metabolic reactions, assisting with DNA replication, initiating responses to stimuli and transporting molecules from one location to another. An alteration to amino acid and protein metabolism coincides with the change in nucleotide metabolism which is required for the replication of genetic information. It also confirms a disruption in cell signaling processes highlighted previously to occurr as a result of changes in lipid and membrane biosynthetic processes.

Anemia is a documented complication of HIV infection associated with decreased patient survival [50]. We identified metabolites potentially related to the treatment of anemia and sickle cell disease suggesting the occurrence of these conditions in patients. As shown in table 3, we detect for example, Leucovorin [metabolite 4 in table 3(i)], which is used in the treatment of anemias and hematological complications. Anemia has been identified as a frequent complication of HIV infection and hemoglobin was also shown by Obirikorang and Yeboah, 2009 [50] to be a predictor for the progression of HIV/AIDS. Leucovorin was detected in the ESImode. After tracing the variable (in this case V1367MZ458.1292) in the dataset using individual metabolite trend plots prepared in MassLynx v4.1 software, this variable was found to be present in mostly treated patients allowing us to infer the presence of a specific condition and its treatment in those patients. Looking at the particular patient's files where the variable was present, we were able to confirm that the patient was receiving treatment for anemia. We detect breakdown products of hemoglobin which serve as markers for urinary tract function. Hemoglobin breakdown products such as globin are known to be converted to amino acids which 
participate in metabolism or the formation of new proteins. It is quite interesting to observe how metabolites of blood-related conditions coincide with protein metabolism changes noted in the preceding paragraph.

Psoriasis is a skin condition associated amongst others, with HIV infection. This condition is associated with cardiovascular disease, a common complication of HIV-infected and treated individuals [51]. In this study we detect DHNA, an anthraquinone used to treat psoriasis. Other therapeutics given to the HIV+ individuals of this study include for example antifungal agents such as clotrimazole. Immunocompromised patients are burdened with opportunistic infections making the detection of metabolites which are linked to these types of therapeutics valid. We also detected metabolites suggesting the use of anti-inflammatory, anti-pyretic and antirheumatic agents used to treat common HIV-related conditions. HIV-infected individuals are known to be under oxidative stress [52]. We detected 5'deoxyadenosine which is a marker of oxidative damage. Taxifolin and chlorogenic acid have antioxidant properties and were also detected implying a counter response to oxidative stress. In a gas chromatography mass spectrometry (GC-MS) metabonomics study investigating HIV-induced mitochondrial dysfunction in asymptomatic HIV-infected patients, Williams et al (2012) [3] detected two metabolites linked to "self-treatment". GC-MS detects volatile compounds [53]. Most metabolites in nature are polar and non-volatile [53] as is the metabolites of sera [40]. Because GC requires samples to be volatile, the process of volatilization could have contributed to the failure to detect more "self treatments" by the technique. Inferring the treatment of HIV-related complications was made here after tracking the specific metabolite back to the actual sample in the dataset and reviewing the patient's status i.e. HIV negative, HIV+ and/or HIV+HAART + . Where treatment related metabolites were detected, the patients were treatment-experienced. Metabonomics therfore has the potential to provide real phenotypic patient information.

These findings imply that SPE in the form of Ostro ${ }^{\mathrm{TM}}$ plates is recommended for biofluid metabolome extraction because it eliminates large molecules (proteins and phospholipids) that have been shown to mask metabolites that are analyzed using UPLC-MS. Ultra performance LC-MS proved ideal for biofluid metabonomics because of its increased sensitivity and resolution to detect subtle metabolic disturbances. Based on data presented here the approach could find use in biomarker identification and therefore disease diagnosis and prognosis as well as HIV/AIDS management i.e. monitoring adherence to treatment, treatment success/failure and linking specific drugs to specific metabolic complications. 


\section{CONCLUSION}

Shown here for the first time is an easy SPE protocol which allowed for the collection of reproducible, reliable UPLC-MS data which in turn distinguished HIV-influenced compared to therapy-induced metabolic changes. UPLC-MS detected changes in lipid and energy metabolism in negative ionization mode whilst metabolites indicative of the treatment of HIV-associated conditions were mainly evident in positive ionization mode. The biological role of the metabolites causing group differentiation coincides well with that reported in the literature. The mean plots already gave an indication of an increase or decrease in metabolite levels while chemometrics confirmed the visual observations. The quantification of metabolite changes as a necessary next step will be simplified by either a targeted analysis or a decision on the specific metabolite or groups of metabolites to investigate in order to identify useful standards and/or molecules for sample spiking. Quantification should contribute to the clarification of the exact HIV-related mechanisms involved in metabolite increases or decreases. This study presented an easy sample preparation protocol designed for minimal sample handling that favoured quality metabonomics data collection, which is important for clinically relevant biomarker identification. The end use of mass spectrometric metabonomics should eventually be a clinical application, detecting biomarkers of value in diagnostics, prognostics or disease management. The detection of metabolites related to therapy implies a strong role for MS-metabonomics in HIV/AIDS management by monitoring the success/failure of specific treatment regimens, patient adherence and linking specific treatment regimens to particular metabolic complications. The ability to infer additional information from the data suggests an added advantage to metabonomics, in particular the ability to screen randomly and then go back to the sample group and determine whether the conclusions/inferences correlate to the patient's reality. 


\section{LIST OF ABBREVIATIONS}

\begin{tabular}{|c|c|}
\hline ANOVA & Analysis of Variance \\
\hline ATP & Adenosine Triphosphate \\
\hline BPI & Base Peak Ion \\
\hline CSIR & Council for Scientific and Industrial Research \\
\hline $\mathrm{C}$ & Carbon \\
\hline $\mathrm{Da}$ & Dalton \\
\hline DHNA & 1,4-Dihydroxy-2-naphthoic acid \\
\hline DNA & Deoxyribonucleic acid \\
\hline dNTPs & Deoxynucleotide triphosphates \\
\hline ESI- & Electrospray ionization, negative mode \\
\hline ESI+ & Electrospray ionization, positive mode \\
\hline $\mathrm{H}$ & Hydrogen \\
\hline HIV & Human Immunodeficiency Virus \\
\hline $\mathrm{HIV}+$ & HIV positive \\
\hline HAART & Highly Active Antiretroviral Therapy \\
\hline HMDB & Human Metabolome Database \\
\hline LDA & Linear Discriminant Analysis \\
\hline MMDB & Molecular Modeling Database \\
\hline MRC & Medical Research Council \\
\hline MS & Mass Spectrometry \\
\hline MSI & Metabolomics Standards Initiative \\
\hline $\mathrm{N}$ & Nitrogen \\
\hline NIST & National Institute of Standards and Technology \\
\hline NRF & National Research Foundation \\
\hline NRTIs & Nucleoside/Nucleotide Reverse Transcriptase Inhibitors \\
\hline NNRTIs & Non- Nucleoside/Nucleotide Reverse Transcriptase Inhibitors \\
\hline $\mathrm{O}$ & Oxygen \\
\hline PCA & Principal component analysis \\
\hline
\end{tabular}




$\begin{array}{ll}\text { PDA } & \begin{array}{l}\text { Photodiode Array } \\ \text { QC }\end{array} \\ \text { RNA } & \text { Quality Control } \\ \text { S } & \text { Ribonucleic acid } \\ \text { SPE } & \text { Sulfur } \\ \text { TIA } & \text { Technology Innovation Agency } \\ \text { UPLC-MS } & \text { Ultra Performance Liquid Chromatography Mass Spectrometry } \\ \text { XS } & \text { Extended Statistics }\end{array}$

\section{CONFLICT OF INTEREST}

The authors declare no conflict of interest.

\section{ACKNOWLEDGEMENTS}

This study was supported by grants from the Medical Research Council (MRC), Technology Innovation Agency (TIA) and the National Research Foundation (NRF) of South Africa.

Aurelia Williams performed the study, analyzed and interpreted the data as well as wrote the article. Khanyisile Kgoadi performed the study, analyzed data and wrote the article. Francois Steffens analyzed the data and wrote the article. Paul Steenkamp collected and analyzed data as well as wrote the article. Debra Meyer was responsible for the design of the project, interpreted the data and wrote the article. All individuals listed as authors therefore contributed substantially to the design, performance, analysis, and reporting of the work. 


\section{REFERENCES}

[1] Couture, P. HIV \& Metabolism:What Are the Complications? The Canadian Journal of CME., 2005, $65-67$.

[2] Brennan-Benson, P. Metabolic and cardiovascular complications of HIV. Medicine., 2009, 37, 348351.

[3] Williams, A.; Koekemoer, G.; Lindeque, Z.; Reinecke, C.; Meyer, D. Qualitative serum organic acid profiles of HIV-infected individuals not on antiretroviral treatment. Metabolomics., 2012, 8, 804-818.

[4] Beisel, W. R. Interrelated changes in host metabolism during generalized infectious illness. Am. J. Clin. Nutr., 1972, 25, 1254-1260.

[5] Wolowczuk, I.; Verwaerde, C.; Viltart, O.; Delanoye, A.; Delacre, M.; Pot, B.; Grangette, C. Feeding our immune system: impact on metabolism. Clin. Dev. Immunol., 2008, 2008, 639803.

[6] Mathis, D.; Shoelson, S. E. Immunometabolism: an emerging frontier. Nat. Rev. Immunol., 2011, 11, 81-83.

[7] Hewer, R.; Vorster, J.; Steffens, F. E.; Meyer, D. Applying biofluid 1H NMR-based metabonomic techniques to distinguish between HIV-1 positive/AIDS patients on antiretroviral treatment and HIV-1 negative individuals. J. Pharm. Biomed. Anal., 2006, 41, 1442-1446.

[8] Jevtović, D.; Dragović, G.; Salemović, D.; Ranin, J.; Djurković-Djaković, O. The metabolic syndrome, an epidemic among HIV-infected patients on HAART. Biomedicine \& Pharmacotherapy., 2009, 63, 337-342.

[9] Powderly, W. Metabolic Complications Associated with HIV Infection and Antiretroviral Therapy. AIDS Patient Care STDS., 2004, 18, 431-435.

[10] Slama, L.; Le Camus, C.; Serfaty, L.; Pialoux, G.; Capeau, J.; Gharakhanian, S. Metabolic disorders and chronic viral disease: The case of HIV and HCV. Diabetes Metab., 2009, 35, 1-11.

[11] Alberti, K. G.; Zimmet, P.; Shaw, J. Metabolic syndrome--a new world-wide definition. A Consensus Statement from the International Diabetes Federation. Diabet. Med., 2006, 23, 469-480.

[12] Pascal, S.; Resnick, L.; Barker, W. W.; Loewenstein, D.; Yoshii, F.; Chang, J.; Boothe, T.; Sheldon, J.; Duara, R. Metabolic Asymmetries in Asymptomatic HIV-1 Seropositive Subjects: Relationship to Disease Onset and MRI Findings. J. Nucl. Med., 1991, 32, 1725-1729. 
[13] Grunfeld, C.; Kotler, D. P.; Hamadeh, R.; Tierney, A.; Wang, J.; Pierson, R. N. Hypertriglyceridemia in the acquired immunodeficiency syndrome. Am. J. Med., 1989, 86, 27-31.

[14] Grunfeld, C.; Pang, M.; Doerrler, W.; Shigenaga, J. K.; Jensen, P.; Feingold, K. R. Lipids, lipoproteins, triglyceride clearance, and cytokines in human immunodeficiency virus infection and the acquired immunodeficiency syndrome. Journal of Clinical Endocrinology \& Metabolism., 1992, 74, 1045-1052.

[15] Sitole, L. J.; Williams, A. A.; Meyer, D. Metabonomic analysis of HIV-infected biofluids. Mol. Biosyst., 2013, 9, 18-28.

[16] Villas-Boas, S.G.; Roessner, U.; Hansen, M.A.E.; Smadsgaard, J.; Nielson, J. Metabolomics in Humans and other mammals. In: Metabolome Analysis: An introduction.; John Wiley \& Sons, 2007; 253-288.

[17]Zhang, M.; Versalovic, J. HIV update. Diagnostic tests and markers of disease progression and response to therapy. Am. J. Clin. Pathol., 2002, 118 Suppl, S26-32.

[18] Kanekar, A. Biomarkers predicting progression of human immunodeficiency virus-related disease. $J$. Clin. Med. Res., 2010, 2, 55-61.

[19] Beger, R.; Colatsky, T. Metabolomics data and the biomarker qualification process. Metabolomics., 2012, 8, 2-7.

[20] Keane, N.; John, M. Biomarkers of natural and vaccine immunity against HIV. Biomark Med., 2011, 5, 113-116.

[21] Ghannoum, M. A.; Mukherjee, P. K.; Jurevic, R. J.; Retuerto, M.; Brown, R. E.; Sikaroodi, M.; Webster-Cyriaque, J.; Gillevet, P. M. Metabolomics Reveals Differential Levels of Oral Metabolites in HIV-Infected Patients: Toward Novel Diagnostic Targets. OMICS: A Journal of Integrative Biology., 2011, $17,5-15$.

[22] Hollenbaugh, J. A.; Munger, J.; Kim, B. Metabolite profiles of human immunodeficiency virus infected CD4+ T cells and macrophages using LC-MS/MS analysis. Virology., 2011, 415, 153-159.

[23] Schwartz, S. J. How Can the Metabolomic Response to Lycopene (Exposures, Durations, Intracellular Concentrations) in Humans Be Adequately Evaluated? The Journal of Nutrition., 2005, 135, 2040S2041S.

[24] Nováková, L.; Solichová, D.; Solich, P. Advantages of ultra performance liquid chromatography over high-performance liquid chromatography: Comparison of different analytical approaches during analysis of diclofenac gel. Journal of Separation Science., 2006, 29, 2433-2443. 
[25]Zelena, E.; Dunn, W. B.; Broadhurst, D.; Francis-McIntyre, S.; Carroll, K. M.; Begley, P.; Oâ€тмHagan, S.; Knowles, J. D.; Halsall, A.; Wilson, I. D.; Kell, D. B. Development of a Robust and Repeatable UPLCâ^’MS Method for the Long-Term Metabolomic Study of Human Serum. Anal. Chem., 2009, 81, 1357-1364.

[26]Fiehn, O.; Robertson, D.; Griffin, J.; van, d. W.; Nikolau, B.; Morrison, N.; Sumner, L.; Goodacre, R.; Hardy, N.; Taylor, C.; Fostel, J.; Kristal, B.; Kaddurah-Daouk, R.; Mendes, P.; van Ommen, B.; Lindon, J.; Sansone, S. The metabolomics standards initiative (MSI). Metabolomics., 2007, 3, 175-178.

[27] Allanson, J. P.; Biddlecombe, R. A.; Jones, A. E.; Pleasance, S. The Use of Automated Solid Phase Extraction in the '96 well' Format for High Throughput Bioanalysis using Liquid Chromatography Coupled to Tandem Mass Spectrometry. Rapid Communications in Mass Spectrometry., 1996, 10, 811816.

[28] Simpson, H.; Berthemy, A.; Buhrman, D.; Burton, R.; Newton, J.; Kealy, M.; Wells, D.; Wu, D. High throughput liquid chromatography/mass spectrometry bioanalysis using 96-well disk solid phase extraction plate for the sample preparation. Rapid Commun. Mass Spectrom., 1998, 12, 75-82.

[29]Zimmer, D.; Pickard, V.; Czembor, W.; Muller, C. Comparison of turbulent-flow chromatography with automated solid-phase extraction in 96-well plates and liquid-liquid extraction used as plasma sample preparation techniques for liquid chromatography-tandem mass spectrometry. J. Chromatogr., A 1999, $854,23-35$.

[30] Michopoulos, F.; Lai, L.; Gika, H.; Theodoridis, G.; Wilson, I. UPLC-MS-based analysis of human plasma for metabonomics using solvent precipitation or solid phase extraction. J. Proteome Res., 2009, $8,2114-2121$.

[31] Tulipani, S.; Llorach, R.; Urpi-Sarda, M.; Andres-Lacueva, C. Comparative analysis of sample preparation methods to handle the complexity of the blood fluid metabolome: when less is more. Anal. Chem., 2013, 85, 341-348.

[32] Rose, M. J.; Merschman, S. A.; Eisenhandler, R.; Woolf, E. J.; Yeh, K. C.; Lin, L.; Fang, W.; Hsieh, J.; Braun, M. P.; Gatto, G. J.; Matuszewski, B. K. High-throughput simultaneous determination of the HIV protease inhibitors indinavir and L-756423 in human plasma using semi-automated 96-well solid phase extraction and LC-MS/MS. J. Pharm. Biomed. Anal., 2000, 24, 291-305.

[33] Schuster, A.; Burzawa, S.; Jemal, M.; Loizillon, E.; Couerbe, P.; Whigan, D. Quantitative determination of the HIV protease inhibitor atazanavir (BMS-232632) in human plasma by liquid 
chromatography-tandem mass spectrometry following automated solid-phase extraction. $J$. Chromatogr. B. Analyt Technol. Biomed. Life. Sci., 2003, 788, 377-386.

[34] Want, E. J.; Wilson, I. D.; Gika, H.; Theodoridis, G.; Plumb, R. S.; Shockcor, J.; Holmes, E.; Nicholson, J. K. Global metabolic profiling procedures for urine using UPLC-MS. Nat. Protocols., 2010, 5, 1005-1018.

[35]Dunn, W. B.; Broadhurst, D.; Begley, P.; Zelena, E.; Francis-McIntyre, S.; Anderson, N.; Brown, M.; Knowles, J. D.; Halsall, A.; Haselden, J. N.; Nicholls, A. W.; Wilson, I. D.; Kell, D. B.; Goodacre, R. Procedures for large-scale metabolic profiling of serum and plasma using gas chromatography and liquid chromatography coupled to mass spectrometry. Nat. Protocols., 2011, 6, 1060-1083.

[36] Bijlsma, S.; Bobeldijk, I.; Verheij, E. R.; Ramaker, R.; Kochhar, S.; Macdonald, I. A.; van Ommen, B.; Smilde, A. K. Large-scale human metabolomics studies: a strategy for data (pre-) processing and validation. Anal. Chem., 2006, 78, 567-574.

[37]Lin, L.; Yu, Q.; Yan, X.; Hang, W.; Zheng, J.; Xing, J.; Huang, B. Direct infusion mass spectrometry or liquid chromatography mass spectrometry for human metabonomics? A serum metabonomic study of kidney cancer. Analyst., 2010, 135, 2970-2978.

[38]Luque-Garcia, J.; Neubert, T. A. Sample preparation for serum/plasma profiling and biomarker identification by mass spectrometry. Journal of Chromatography A; Advances in Sample Preparation Part II., 2007, 1153, 259-276.

[39] Want, E.; Masson, P. Processing and analysis of GC/LC-MS-based metabolomics data. Methods Mol. Biol., 2011, 708, 277-298.

[40]Lin, L.; Huang, Z.; Gao, Y.; Yan, X.; Xing, J.; Hang, W. LC-MS based serum metabonomic analysis for renal cell carcinoma diagnosis, staging, and biomarker discovery. J. Proteome Res., 2011, 10, 13961405.

[41]Hommes, M. J. T.; Romijn, J. A.; Godfried, M. H.; Eeftinck Schattenkerk, J. K. M.; Buurman, W. A.; Endert, E.; Sauerwein, H. P. Increased resting energy expenditure in human immunodeficiency virusinfected men. Metab. Clin. Exp., 1990, 39, 1186-1190.

[42] Hommes, M.; Romijn, J.; Endert, E.; Sauerwein, H. Resting energy expenditure and substrate oxidation in human immunodeficiency virus (HIV)-infected asymptomatic men: HIV affects host metabolism in the early asymptomatic stage. The American Journal of Clinical Nutrition., 1991, 54, 311-315. 
[43] Macho, A.; Castedo, M.; Marchetti, P.; Aguilar, J. J.; Decaudin, D.; Zamzami, N.; Girard, P. M.; Uriel, J.; Kroemer, G. Mitochondrial dysfunctions in circulating T lymphocytes from human immunodeficiency virus-1 carriers. Blood., 1995, 86, 2481-2487.

[44] Kakuda, T. N.; Brundage, R. C.; Anderson, P. L.; Fletcher, C. V. Nucleoside reverse transcriptase inhibitor-induced mitochondrial toxicity as an etiology for lipodystrophy. AIDS., 1999, 13, 2311-2312.

[45] Kakuda, T. N. Pharmacology of nucleoside and nucleotide reverse transcriptase inhibitor-induced mitochondrial toxicity. Clin. Ther., 2000, 22, 685-708.

[46] Sweet, D.E. Perspective Metabolic Complications of Antiretroviral Therapy. International AIDS Society: Topics in HIV Medicine., 2005, 13, 70-74.

[47] Shedlock, D. J.; Hwang, D.; Choo, A. Y.; Chung, C. W.; Muthumani, K.; Weiner, D. B. HIV-1 viral genes and mitochondrial apoptosis. Apoptosis., 2008, 13, 1088-1099.

[48] Hofhaus, G.; Johns, D. R.; Hurko, O.; Attardi, G.; Chomyn, A. Respiration and growth defects in transmitochondrial cell lines carrying the 11778 mutation associated with Leber's hereditary optic neuropathy. J Biol Chem., 1996, 271, 13155-13161.

[49] Balzarini, J. Effect of antimetabolite drugs of nucleotide metabolism on the anti-human immunodeficiency virus activity of nucleoside reverse transcriptase inhibitors. Pharmacol. Ther., 2000, $87,175-187$.

[50] Obirikorang, C.; Yeboah, F. Blood haemoglobin measurement as a predictive indicator for the progression of HIV/AIDS in resource-limited setting. J. Biomed. Sci., 2009, 16, 102-108.

[51] Ghazizadeh, R.; Tosa, M.; Ghazizadeh, M. Clinical improvement in psoriasis with treatment of associated hyperlipidemia. Am. J. Med. Sci., 2011, 341, 394-398.

[52] Pace, G. W.; Leaf, C. D. The role of oxidative stress in HIV disease. Free Radic. Biol. Med., 1995, 19, $523-528$.

[53] Pasikanti, K. K.; Ho, P. C.; Chan, E. C. Gas chromatography/mass spectrometry in metabolic profiling of biological fluids. J. Chromatogr. B. Analyt Technol. Biomed. Life. Sci., 2008, 871, 202-211.

[54]Beets, C.; Huang, J.; Madala, N.; Dubery, I. Activation of camalexin biosynthesis in Arabidopsis thaliana in response to perception of bacterial lipopolysaccharides: a gene-to-metabolite study. Planta., 2012, 236, 261-272.

[55]Zhang, J.; Bowers, J.; Liu, L.; Wei, S.; Gowda, G. A.; Hammoud, Z.; Raftery, D. Esophageal cancer metabolite biomarkers detected by LC-MS and NMR methods. PLoS One., 2012, 7, e30181. 
[56]Dietmair, S.; Timmins, N. E.; Gray, P. P.; Nielsen, L. K.; Kromer, J. O. Towards quantitative metabolomics of mammalian cells: development of a metabolite extraction protocol. Anal. Biochem., 2010, 404, 155-164.

[57] Sellick, C. A.; Hansen, R.; Stephens, G. M.; Goodacre, R.; Dickson, A. J. Metabolite extraction from suspension-cultured mammalian cells for global metabolite profiling. Nat. Protoc., 2011, 6, 12411249.

[58]Lu, X.; Xu, G. LC-MS Metabonomics Methodology in Biomarker Discovery. In: Biomarker Methods in Drug Discovery and Development. Springer, 2008; pp291-315.

[59] Masson, P.; Alves, A. C.; Ebbels, T. M.; Nicholson, J. K.; Want, E. J. Optimization and evaluation of metabolite extraction protocols for untargeted metabolic profiling of liver samples by UPLC-MS. Anal. Chem., 2010, 82, 7779-7786.

[60] Want, E. J.; O'Maille, G.; Smith, C. A.; Brandon, T. R.; Uritboonthai, W.; Qin, C.; Trauger, S. A.; Siuzdak, G. Solvent-dependent metabolite distribution, clustering, and protein extraction for serum profiling with mass spectrometry. Anal. Chem., 2006, 78, 743-752.

[61]Lin, C.; Wu, H.; Tjeerdema, R.; Viant, M. Evaluation of metabolite extraction strategies from tissue samples using NMR metabolomics. Metabolomics., 2007, 3, 55-67.

[62] Wheaton, J.P.; Chambers, E.E.; Fountain, K.J. Improving the Cleanliness of DBS Extracts using the Ostro 96-well Sample Preparation Plate and Single Step Method. Waters Corporation. 2011, Waters Application Note \#., 720004047EN, 1-6.

[63] Ritchie, M.; Mal, M.; Wong, S. Extraction of Phospholipids from Plasma using Ostro Sample Preparation. Waters Corporation. 2012, Waters Application Note \#., 720004201EN, 1-5.

[64] Hoffman, B. Evaluation of a new sample preparation approach for quantitative bioanalytical LC-MS. Bioanalysis., 2010, 2, 1931-1942. 
Sample+Internal Standard +Solvent

$\downarrow$

Homogenize / Vortex

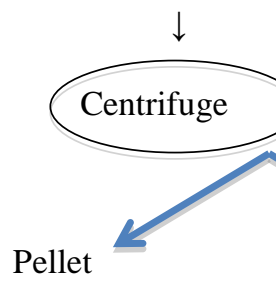

Resuspend in solvent + reextract

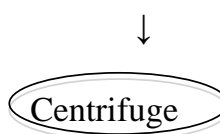

$\downarrow$

Supernatant

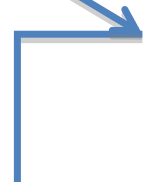

Supernatant

Add water/solvent

analysis

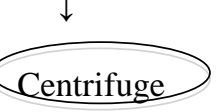

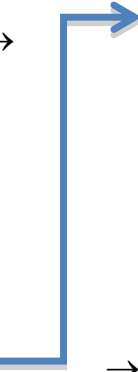

Chromatographic-MS

\section{Ostro $^{\mathrm{TM}}$ Plate Method ${ }^{[62-64]}$}

Chromatographic-MS analysis

Figure 1 Metabolite Extraction Methods.
Place Ostro ${ }^{\mathrm{TM}}$ Plate on

Collection Plate

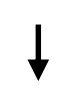

Load Sample

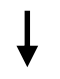

Forcefully add organic solvent

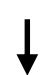

Aspirate $3 \mathrm{X}$

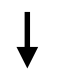

Apply Positive Pressure

$\underline{\text { Other 96-well SPE formats }}^{[27,28,30,32,33]}$

Prepare samples, QCs

Add internal standard

Condition SPE plates

-i.e. sequential washing of plate with solvent/water and/or buffer

Add solvent containing interna

standard to sample + QCs

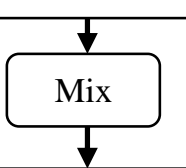

Load sample mixture onto SPE plates
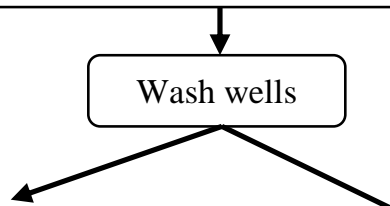

$\downarrow$

Analyze eluates

(UPLC-MS) e analyte under vacuum 
Table 1 Characteristics of the participating donors.

\begin{tabular}{|c|c|c|c|}
\hline & \multicolumn{3}{|c|}{ HIV Status } \\
\hline Characteristic & HIV negative $(\mathrm{n}=16)$ & $\mathrm{HIV}+(\mathrm{n}=13)$ & HIV+HAART+ $(\mathrm{n}=15)$ \\
\hline$\%$ Females & 75.0 & 69.2 & 80.0 \\
\hline$\%$ Males & 25.0 & 30.8 & 20.0 \\
\hline Mean Age $\pm S D$ (years) & $26.7 \pm 6.1$ & $38.5 \pm 8.9$ & $43.2 \pm 11.3$ \\
\hline $\begin{array}{l}\text { Mean CD4 count (cells/ } \mu \text { l blood, } \\
\text { range) }\end{array}$ & Not Determined & $549.3(100-2380)$ & $468.9(204-728)$ \\
\hline Viral Load (copies/ml, range) & Not Determined & $149557(23-350430)$ & $1352(43-3624)$ \\
\hline \multicolumn{4}{|l|}{$\underline{\text { HAART combinations }}$} \\
\hline Unknown & - & - & $5(33.33 \%)$ \\
\hline NRTIs and NNRTIs & - & - & $10(66.66 \%)$ \\
\hline \multicolumn{4}{|c|}{ P-values comparing differences in age among groups } \\
\hline Group comparisons & HIV negative and HIV+ & $\begin{array}{l}\text { HIV negative and } \\
\text { HIV+HAART+ }\end{array}$ & $\begin{array}{c}\text { HIV+ and } \\
\text { HIV+HAART+ }\end{array}$ \\
\hline p-value & 0.000228534 & $1.8539 \mathrm{E}-05$ & 0.24206586 \\
\hline
\end{tabular}




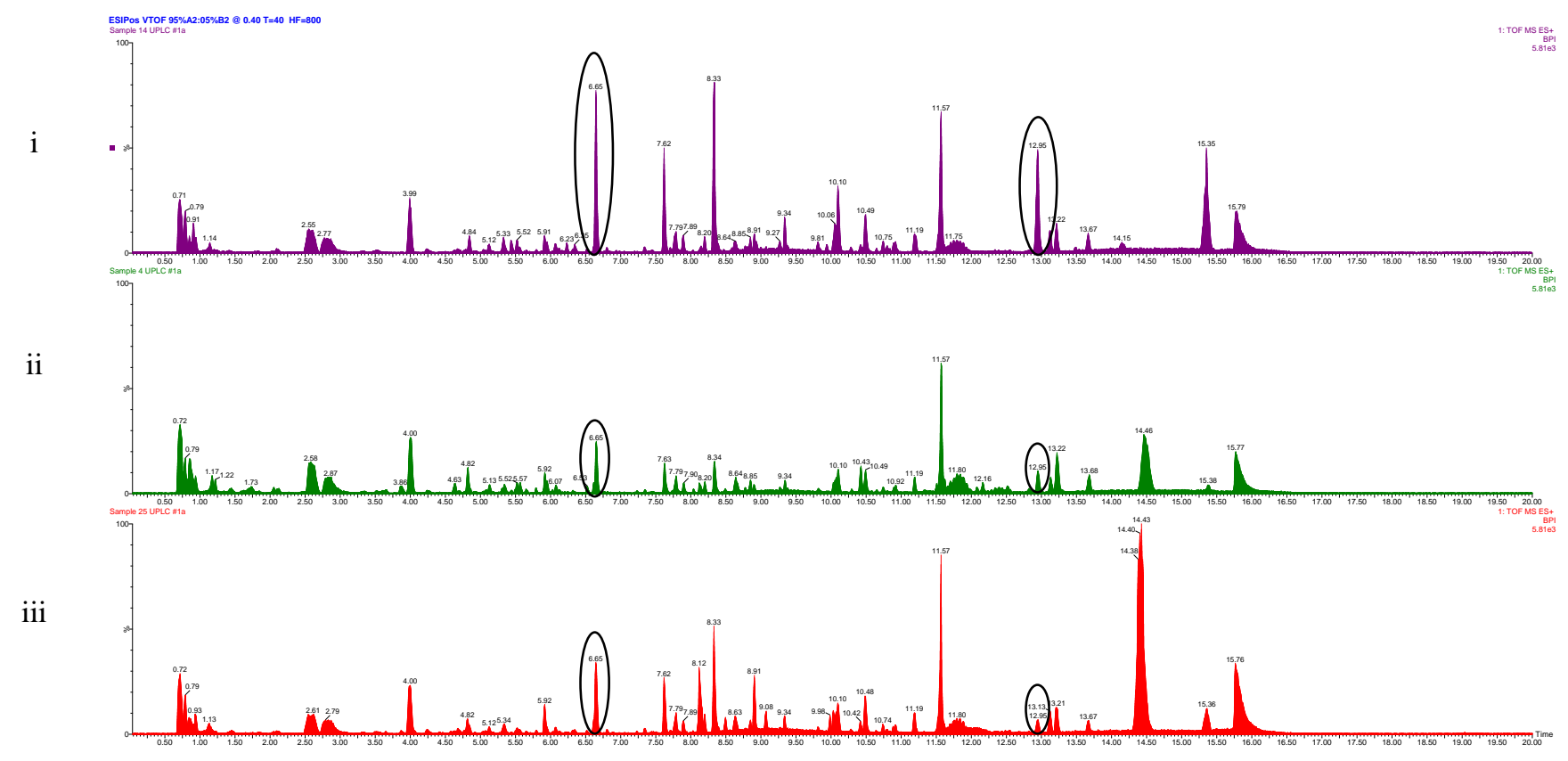

Figure 2 Representative stacked base peak ion (BPI) chromatograms of (i) HIV+HAART+, (ii) HIV+ and (iii) HIV negative sera samples analyzed in ESI+ mode of UPLC-MS. Differences in the three representative groups' metabolites are visible through visual inspection (see representative circles). The use of Ostro $^{\mathrm{TM}}$ plates minimize plasticizers from leaching and yielded improved quality chromatograms compared to Figure S2 where plasticizers and phospholipids were present. 
Table 2 Classification of experimental cases as HIV negative, HIV+ or HIV+HAART+ in ESI- and ESI+ mode, respectively, using stepwise LDA. This statistical tool uses a linear combination of variables to maximize the separation between experimental groups. In ESI- mode shown in [i], 17 HIV negative, 15 HIV+HAART+ and 11 HIV+ cases were analyzed and correctly classified with $100 \%$ accuracy (shaded areas) into their respective groups. Likewise, 15 HIV negative, 14 HIV+HAART+ and 13 HIV+ cases were analyzed and correctly classified with $100 \%$ accuracy (shaded areas) in ESI+ mode [ii]. An explanation for the number of cases analyzed is provided under the "Optimized Metabolite Extraction from Sera using Ostro ${ }^{\text {TM }}$ Plates" section.

\begin{tabular}{|c|c|c|c|c|c|c|}
\hline \multicolumn{7}{|c|}{ i. $\quad$ ESI- Classification Results ${ }^{a}$} \\
\hline & & \multirow[t]{2}{*}{ STATUS } & \multicolumn{3}{|c|}{ Predicted Group Membership } & \multirow[t]{2}{*}{ Total } \\
\hline & & & NEG & POS HAART & POS & \\
\hline \multirow[t]{6}{*}{ Original } & \multirow[t]{3}{*}{ Count } & NEG & 17 & 0 & 0 & 17 \\
\hline & & POS HAART & 0 & 15 & 0 & 15 \\
\hline & & POS & 0 & 0 & 11 & 11 \\
\hline & \multirow[t]{3}{*}{$\%$} & NEG & 100.0 & .0 & .0 & 100.0 \\
\hline & & POS HAART & .0 & 100.0 & .0 & 100.0 \\
\hline & & POS & .0 & .0 & 100.0 & 100.0 \\
\hline
\end{tabular}

a. $100.0 \%$ of original grouped cases correctly classified.

ii. $\quad$ ESI+ Classification Results ${ }^{\mathrm{a}}$

\begin{tabular}{|c|c|c|c|c|c|c|}
\hline & & \multirow[t]{2}{*}{ STATUS } & \multicolumn{3}{|c|}{ Predicted Group Membership } & \multirow[t]{2}{*}{ Total } \\
\hline & & & NEG & POS HAART & POS & \\
\hline \multirow[t]{6}{*}{ Original } & \multirow[t]{3}{*}{ Count } & NEG & 15 & 0 & 0 & 15 \\
\hline & & POS HAART & 0 & 14 & 0 & 14 \\
\hline & & POS & 0 & 0 & 13 & 13 \\
\hline & \multirow[t]{3}{*}{$\%$} & NEG & 100.0 & .0 & .0 & 100.0 \\
\hline & & POS HAART & .0 & 100.0 & .0 & 100.0 \\
\hline & & POS & .0 & .0 & 100.0 & 100.0 \\
\hline
\end{tabular}

a. $100.0 \%$ of original grouped cases correctly classified. 


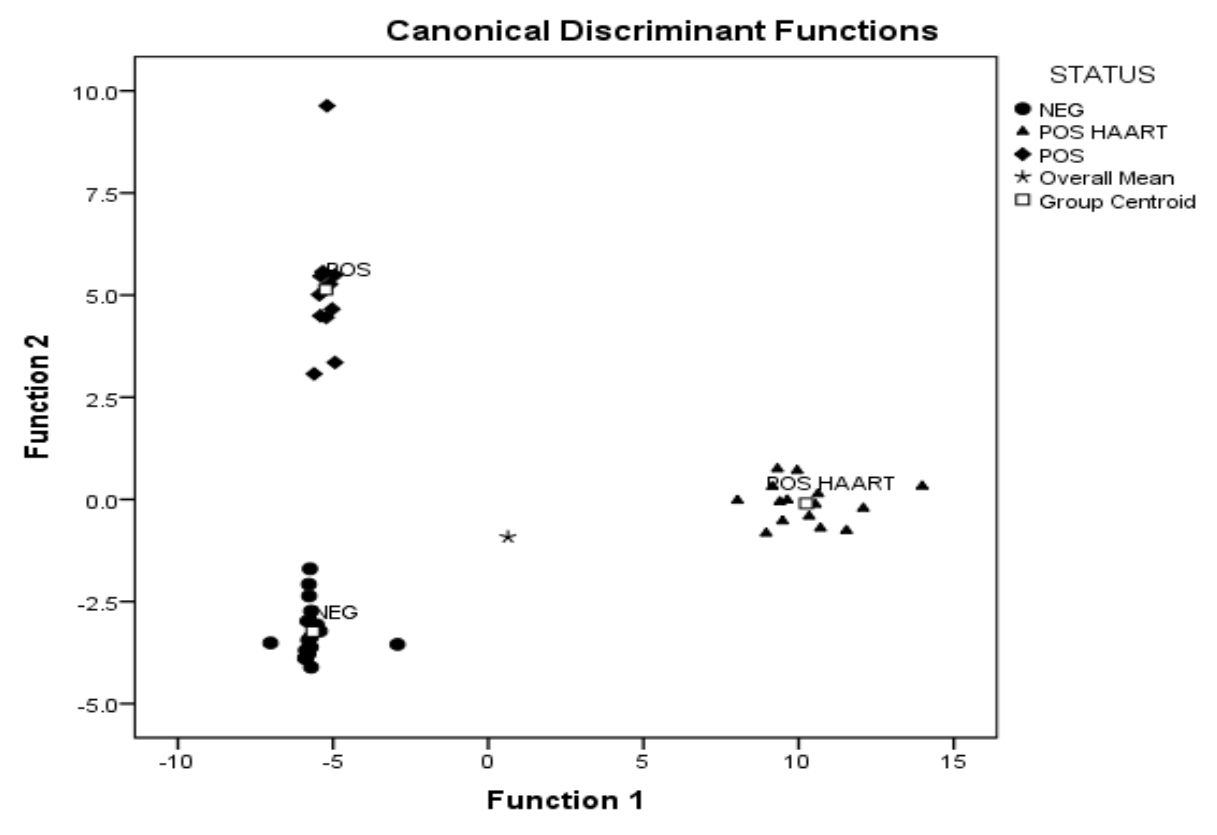

i. ESI-

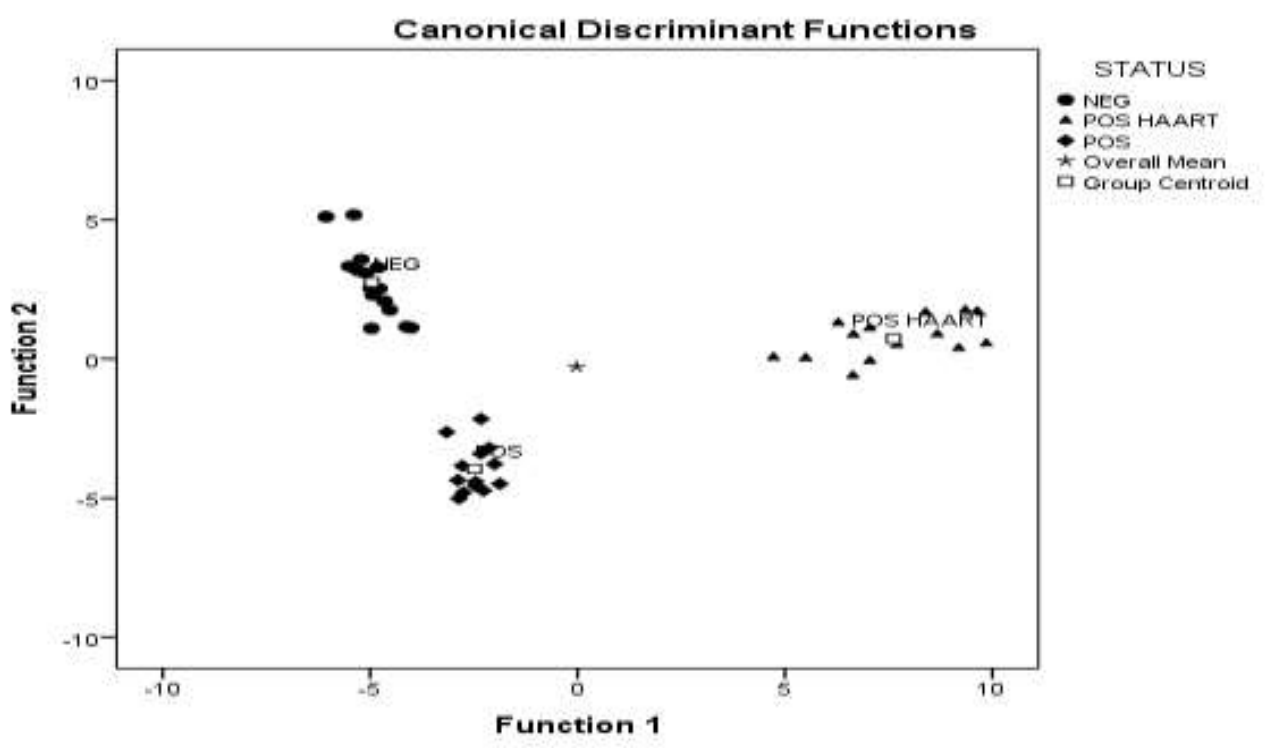

ii. $\quad$ ESI+

Figure 3 Scatter plot of the discriminant functions for the HIV negative, HIV+ and HIV+HAART+ groups. Here the summed responses of every individual used in the study, is reflected. Shown in [i] and [ii] are the ESI- and ESI+ data respectively showing the HIV+HAART group to be most differentiated from the HIV negative and HIV+ groups respectively. 
Table 3 Metabolites from the ESI- [i] and ESI+ [ii] mode data identified through LDA as causing group variances. The differences in group means of these metabolites were also calculated through ANOVA.

i. ESI- mode

\begin{tabular}{|c|c|c|c|c|c|c|c|}
\hline & $\begin{array}{l}\underline{\text { LDA variable }} \\
\underline{(\mathrm{m} / \mathrm{z})}\end{array}$ & $\begin{array}{l}\text { Retention } \\
\text { Time }\end{array}$ & $\begin{array}{l}\text { p-value } \\
\underline{\text { (ANOVA) }}\end{array}$ & $\begin{array}{l}\text { Metabolite ID as per } \\
\text { database/library searches }\end{array}$ & $\begin{array}{l}\text { Common } \\
\underline{\text { name }}\end{array}$ & CompoundClass & $\underline{\text { Biological Role }}$ \\
\hline 1. & V0274MZ213.9635 & 7.8494 & 0.000 & Methyl laurate & $\begin{array}{l}\text { Methyl } \\
\text { dodecanoate }\end{array}$ & $\begin{array}{l}\text { Lipids } \\
\text {-Fatty acid esters }\end{array}$ & $\begin{array}{l}\text { Cell signalling } \\
\text { Fuel and energy source } \\
\text { Fuel and energy storage } \\
\text { Membrane } \\
\text { integrity/stability }\end{array}$ \\
\hline 2. & V0822MZ343.2067 & 9.4372 & 0.020 & $\begin{array}{l}1-[(2- \\
\text { Chlorophenyl)(diphenyl)methyl]-1H- } \\
\text { imidazole }\end{array}$ & Clotrimazole & $\begin{array}{l}\text {-Aromatic } \\
\text { heterpolycyclic } \\
\text { compounds } \\
\text {-Diphenyl } \\
\text { methanes }\end{array}$ & $\begin{array}{l}\text { Antifungal medication } \\
\text { Used to treat sickle cell } \\
\text { disease }\end{array}$ \\
\hline 3. & V1105MZ411.782 & 9.4796 & 0.016 & $\begin{array}{l}\text { (3beta,24E)-Stigmasta-5,24(28)-dien- } \\
\text { 3-ol }\end{array}$ & Fucosterol & $\begin{array}{l}\text { Lipids } \\
\text {-Steroids and } \\
\text { steroid derivatives }\end{array}$ & $\begin{array}{l}\text { Cell signalling } \\
\text { Fuel and energy source } \\
\text { Fuel and energy storage } \\
\text { Membrane } \\
\text { integrity/stability }\end{array}$ \\
\hline
\end{tabular}




\begin{tabular}{|c|c|c|c|c|c|c|c|}
\hline 4. & V1276MZ458.1392 & 5.073 & 0.016 & $\begin{array}{l}\mathrm{N} \text {-(4-\{[(2-Amino-5-methyl-4-oxo- } \\
\text { 1,4,5,6,7,8-hexahydro-6- } \\
\text { pteridinyl)methyl]amino }\} \text { benzoyl)- } \\
\text { D-glutamic acid }\end{array}$ & Leucovorin & $\begin{array}{l}\text { Pteridines and } \\
\text { derivatives }\end{array}$ & $\begin{array}{l}\text { Treatment of anemias and } \\
\text { hematological } \\
\text { complications linked to } \\
\text { folic acid deficiency }\end{array}$ \\
\hline 5. & V1367MZ480.0522 & 8.1732 & 0.000 & Methyl hentriacontanoate & \multicolumn{3}{|c|}{ No information } \\
\hline 6. & V1376MZ481.0554 & 8.1757 & 0.000 & $\begin{array}{l}\text { Cytidine } 5 \text { '-(tetrahydrogen } \\
\text { triphosphate) }\end{array}$ & $\begin{array}{l}\text { Cytidine } \\
\text { triphosphate }\end{array}$ & 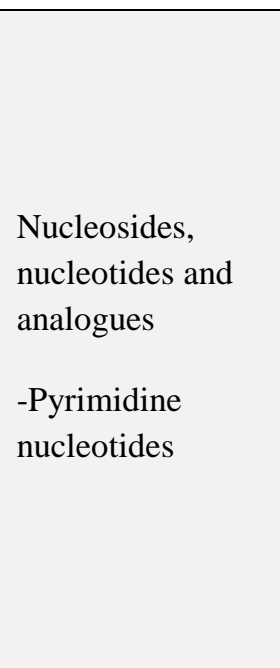 & $\begin{array}{l}\text { Cell signalling } \\
\text { Energy source } \\
\text { Membrane component } \\
\text { Phospholipid synthesis } \\
\text { Membrane } \\
\text { integrity/stability } \\
\text { Pyrimidine metabolism } \\
\text { Transcription/translation } \\
\text { Amino sugar metabolism }\end{array}$ \\
\hline 7. & V0398MZ251.0939 & 6.3542 & 0.079 & 2'-Deoxyadenosine & $\begin{array}{l}5 \text { '-Deoxy- } \\
\text { adenosine }\end{array}$ & $\begin{array}{l}\text { Nucleosides, } \\
\text { nucleotides and } \\
\text { analogues }\end{array}$ & $\begin{array}{l}\text { Component of DNA } \\
\text { Marker for oxidative } \\
\text { damage }\end{array}$ \\
\hline
\end{tabular}




\begin{tabular}{|c|c|c|c|c|c|c|c|}
\hline & & & & & & $\begin{array}{l}\text {-Purine } \\
\text { nucleotides }\end{array}$ & \\
\hline 8. & V0806MZ339.2316 & 13.3905 & 0.057 & $\begin{array}{l}\text { 2,6-Di-O-phosphonohex-2- } \\
\text { ulofuranose }\end{array}$ & \multicolumn{3}{|c|}{ No information } \\
\hline 9. & V0857MZ353.2123 & 11.9254 & 0.056 & $\begin{array}{l}(1 \mathrm{~S}, 3 \mathrm{R}, 4 \mathrm{R}, 5 \mathrm{R})-3-\{[3-(3,4- \\
\text { Dihydroxyphenyl)acryloyl]oxy }\}- \\
1,4,5- \\
\text { trihydroxycyclohexanecarboxylic } \\
\text { acid }\end{array}$ & $\begin{array}{l}\text { Chlorogenic } \\
\text { acid }\end{array}$ & $\begin{array}{l}\text { Aromatic } \\
\text { homonocyclic } \\
\text { compounds } \\
\text {-Cyclic alcohols } \\
\text { and derivatives }\end{array}$ & $\begin{array}{l}\text { Biosynthetic intermediate } \\
\text { in lignin (antioxidant) } \\
\text { synthesis } \\
\text { Limits release of glucose } \\
\text { into bloodstream after a } \\
\text { meal } \\
\text { Antihypertensive effects } \\
\text { to minimize strokes and } \\
\text { cardiovascular mortalities }\end{array}$ \\
\hline 10. & V0641MZ305.0963 & 5.9993 & 0.403 & $\begin{array}{l}\text { 2-(3,4,5-Trihydroxyphenyl)-3,5,7- } \\
\text { chromanetriol }\end{array}$ & $\begin{array}{l}(-) \text { - } \\
\text { Epigallocatechin }\end{array}$ & Flavonoid & $\begin{array}{l}\text { Nutriceutical with anti- } \\
\text { cancer, anti-tumor and } \\
\text { anti-inflammatory activity }\end{array}$ \\
\hline 11. & V1192MZ437.0222 & 6.6879 & 0.538 & - & $\begin{array}{l}\text { Nanocosanoic } \\
\text { acid }\end{array}$ & $\begin{array}{l}\text { Lipids } \\
\text {-Fatty acid }\end{array}$ & $\begin{array}{l}\text { Cell signalling } \\
\text { Fuel and energy storage } \\
\text { Fuel and energy source } \\
\text { Membrane } \\
\text { integrity/stability }\end{array}$ \\
\hline
\end{tabular}


i. $\mathrm{ESI}+$ mode

\begin{tabular}{|c|c|c|c|c|c|c|c|}
\hline & $\underline{\text { LDA variable }(\mathrm{m} / \mathrm{z})}$ & $\frac{\text { Retention }}{\underline{\text { Time }}}$ & $\begin{array}{l}\text { p-value } \\
\underline{\text { (ANOVA) }}\end{array}$ & $\begin{array}{l}\text { Metabolite ID as per } \\
\text { database/library searches }\end{array}$ & Common name & Compound Class & Biological Role \\
\hline 12. & V1658MZ306.0295 & 8.1739 & 0.000 & $\begin{array}{l}(2 \mathrm{R}, 3 \mathrm{R})-2-(3,4- \\
\text { Dihydroxyphenyl)-3,5,7- } \\
\text { trihydroxy-2,3-dihydro-4H- } \\
\text { chromen-4-one }\end{array}$ & Taxifolin & Flavonoid & $\begin{array}{l}\text { Antiviral and antibacterial } \\
\text { activity } \\
\text { Inhibits tumor development } \\
\text { in animals } \\
\text { Inactivation of cytotoxic } \\
\text { substances } \\
\text { Anti-diabetes effect } \\
\text { Prevents osmotic pressure in } \\
\text { hyperlipidermia } \text { etc } \\
\text { Radical scavenger }\end{array}$ \\
\hline 13. & V1496MZ283.1159 & 5.0752 & 0.005 & $\begin{array}{l}\text { 2-Amino-9-pentofuranosyl- } \\
\text { 3,9-dihydro-6H-purin-6-one }\end{array}$ & \multicolumn{3}{|c|}{ No information } \\
\hline 14. & V1544MZ288.0421 & 9.9799 & 0.006 & $\begin{array}{l}\text { 2-(Hydroxymethyl)phenyl } \\
\text { hexopyranoside }\end{array}$ & Salicin & $\begin{array}{l}\text { Carbohydrates } \\
\text { and carbohydrate } \\
\text { conjugates } \\
\text {-Glycosyl } \\
\text { compounds }\end{array}$ & $\begin{array}{l}\text { Anti-inflammatory } \\
\text { Antipyretic } \\
\text { Antirheumatic } \\
\text { Glycolysis/ Gluconeogenesis } \\
\text { Biosynthesis of }\end{array}$ \\
\hline
\end{tabular}




\begin{tabular}{|c|c|c|c|c|c|c|c|}
\hline & & & & & & & $\begin{array}{l}\text { phenylpropanoids } \\
\text { Phosphotransferase system }\end{array}$ \\
\hline 15. & V2199MZ433.366 & 14.3574 & 0.000 & 3,5-Diiodo-L-tyrosine & $\begin{array}{l}\text { L- } \\
\text { Diiodotyrosine }\end{array}$ & $\begin{array}{l}\text { Amino } \\
\text { acids,peptides and } \\
\text { derivatives }\end{array}$ & $\begin{array}{l}\text { Amino acid and protein } \\
\text { biosynthesis } \\
\text { Hyperthyroidism } \\
\text { (biosynthesis of thyroid } \\
\text { hormones) } \\
\text { Chronic kidney/ renal disease }\end{array}$ \\
\hline 16. & V0179MZ564.4313 & 14.5494 & 0.000 & Tetracontane & n-Tetracontane & \multicolumn{2}{|c|}{ No information } \\
\hline 17. & V1007MZ205.1216 & 10.6055 & 0.001 & $\begin{array}{l}\text { 1,4-Dihydroxy-2-naphthoic } \\
\text { acid }\end{array}$ & DHNA & No information & $\begin{array}{l}\text { Precursor of vitamin } \mathrm{K} \text { in } \\
\text { bacteria } \\
\text { Stimulates bifidobacteria } \\
\text { growth, improves intestinal } \\
\text { conditions in the human } \\
\text { intestine }\end{array}$ \\
\hline 18. & V0542MZ675.813 & 5.3449 & 0.015 & $\begin{array}{l}\text { (2R)-1-(Palmitoyloxy)-3- } \\
\text { (phosphonooxy)-2-propanyl } \\
\text { (9Z)-9-octadecnoate }\end{array}$ & $\begin{array}{l}\text { 1- } \\
\text { Hexadecanoyl- } \\
\text { 2-(9Z- } \\
\text { octadecenoyl)- } \\
\text { sn-glycerol 3- } \\
\text { diphosphate } \\
\text { PPA(16:0/18:1( } \\
9 Z))\end{array}$ & No information & $\begin{array}{l}\text { Cell Signalling } \\
\text { Fuel and energy source } \\
\text { Fuel and energy storage } \\
\text { Phoshpholipid biosynthesis } \\
\text { Membrane component } \\
\text { Membrane integrity/ stability }\end{array}$ \\
\hline
\end{tabular}




\begin{tabular}{|c|c|c|c|c|c|c|c|}
\hline 19. & V2473MZ516.3383 & 7.3946 & $\begin{array}{l}\text { Not } \\
\text { available }\end{array}$ & $\begin{array}{l}\text { 2- } \\
\{[(3 a l p h a, 5 b e t a, 6 b e t a, 7 b e t a, \\
8 x i, 9 x i, 14 x i)-3,6,7- \\
\text { Trihydroxy-24-oxocholan- } \\
\text { 24-yl]amino }\} \text { ethanesulfonic } \\
\text { acid }\end{array}$ & \multicolumn{3}{|c|}{ No information } \\
\hline 20. & V1387MZ268.3745 & 6.6322 & 0.650 & $\begin{array}{l}\text { 9-Pentofuranosyl-9H-purin- } \\
\text { 6-amine }\end{array}$ & \multicolumn{3}{|c|}{ No information } \\
\hline 21. & V0287MZ595.2893 & 11.738 & 0.616 & $\begin{array}{l}\text { 3-[2-[(E)-[3-(2- } \\
\text { carboxyethyl)-5-[(3-ethyl-4- } \\
\text { methyl-5-oxo-pyrrolidin-2- } \\
\text { yl)methyl]-4-methyl-pyrrol- } \\
\text { 2-ylidene]methyl]-5-[(4- } \\
\text { ethyl-3-methyl-5-oxo- } \\
\text { pyrrolidin-2-yl)methyl]-4- } \\
\text { methyl-1H-pyrrol-3- } \\
\text { yl]propanoic acid }\end{array}$ & $\begin{array}{l}\text { L-Urobilin or } \\
\text { Stercobilin }\end{array}$ & $\begin{array}{l}\text { Aromatic } \\
\text { heteropolycyclic } \\
\text { compounds } \\
\text {-Tetrapyrroles and } \\
\text { derivatives }\end{array}$ & $\begin{array}{l}\text { Product of heme/hemoglobin } \\
\text { degradation } \\
\text { Indicator of urinary tract } \\
\text { function }\end{array}$ \\
\hline
\end{tabular}

Metabolite below detection hindering p-value calculation 


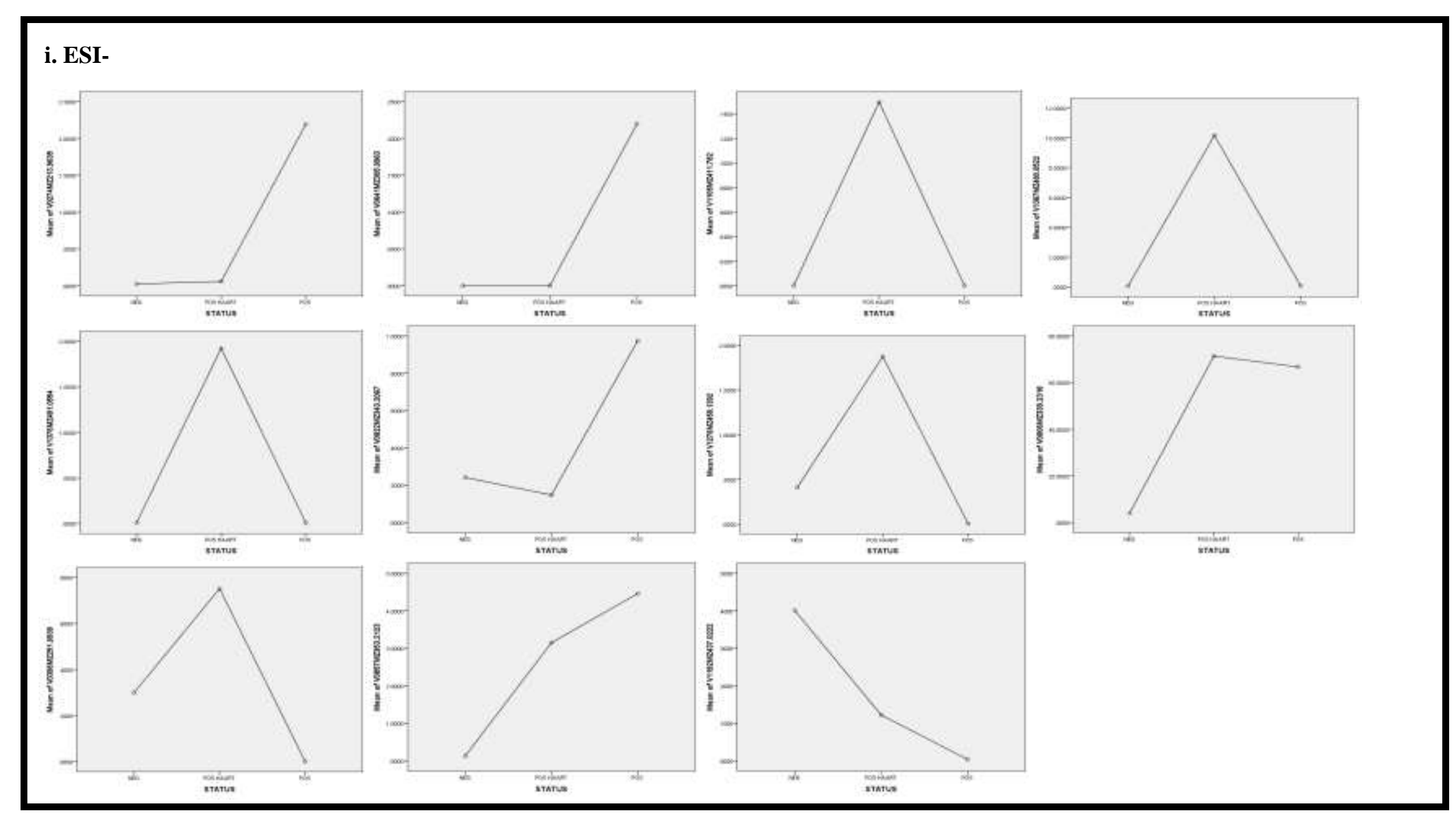




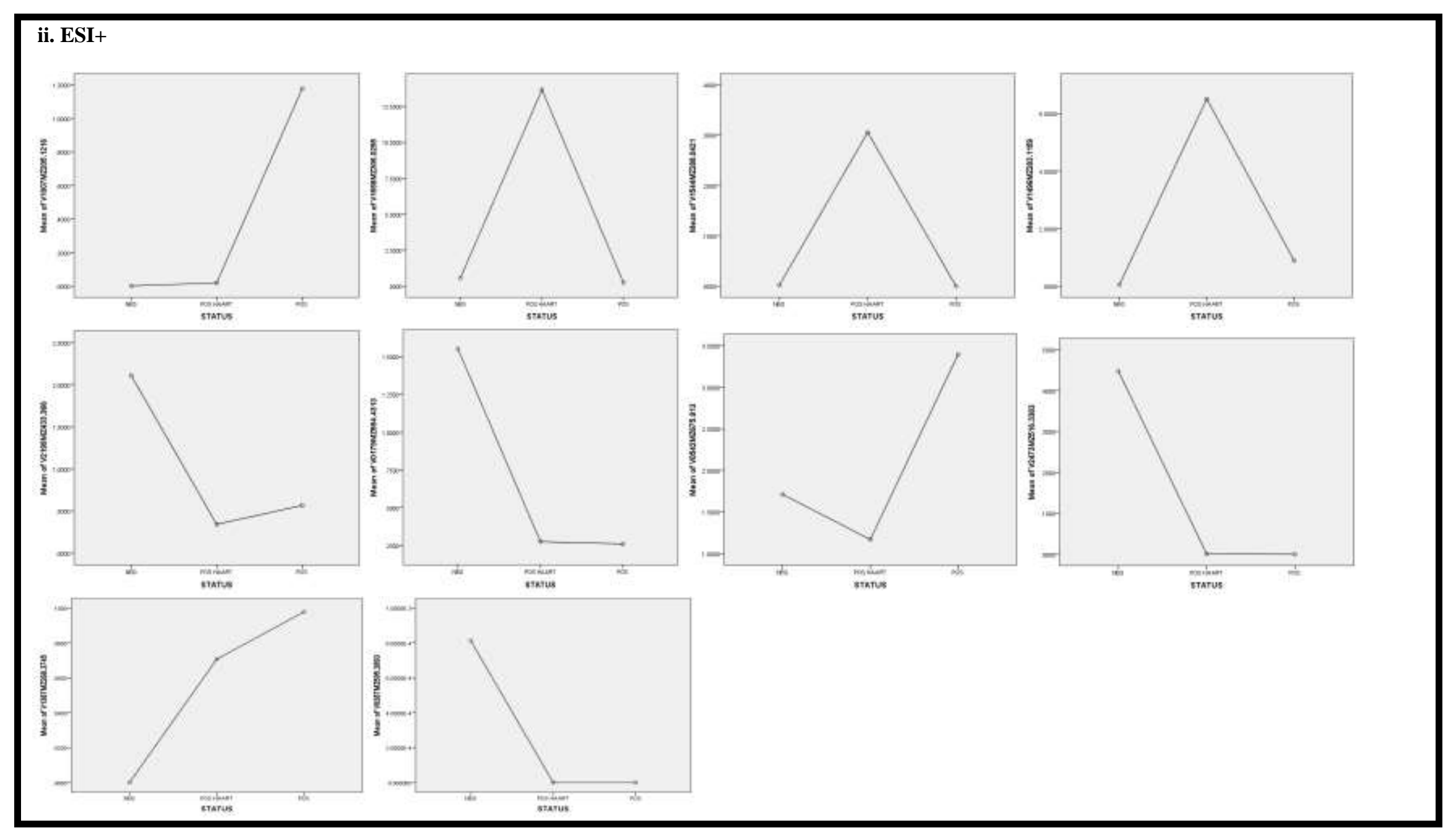

Figure 4 Changes in the mean levels of metabolites extracted from the sera of HIV negative, HIV+ and HIV+HAART+ individuals. Metabolites detected in (i) ESI negative and (ii) ESI+ mode are shown. Mean plots are arranged from left to right as influenced by HIV, HAART and/or a combination of HIV and treatment. Shifts in the levels of the variables among the three groups are visible. 


\section{Supportive/Supplementary Material}

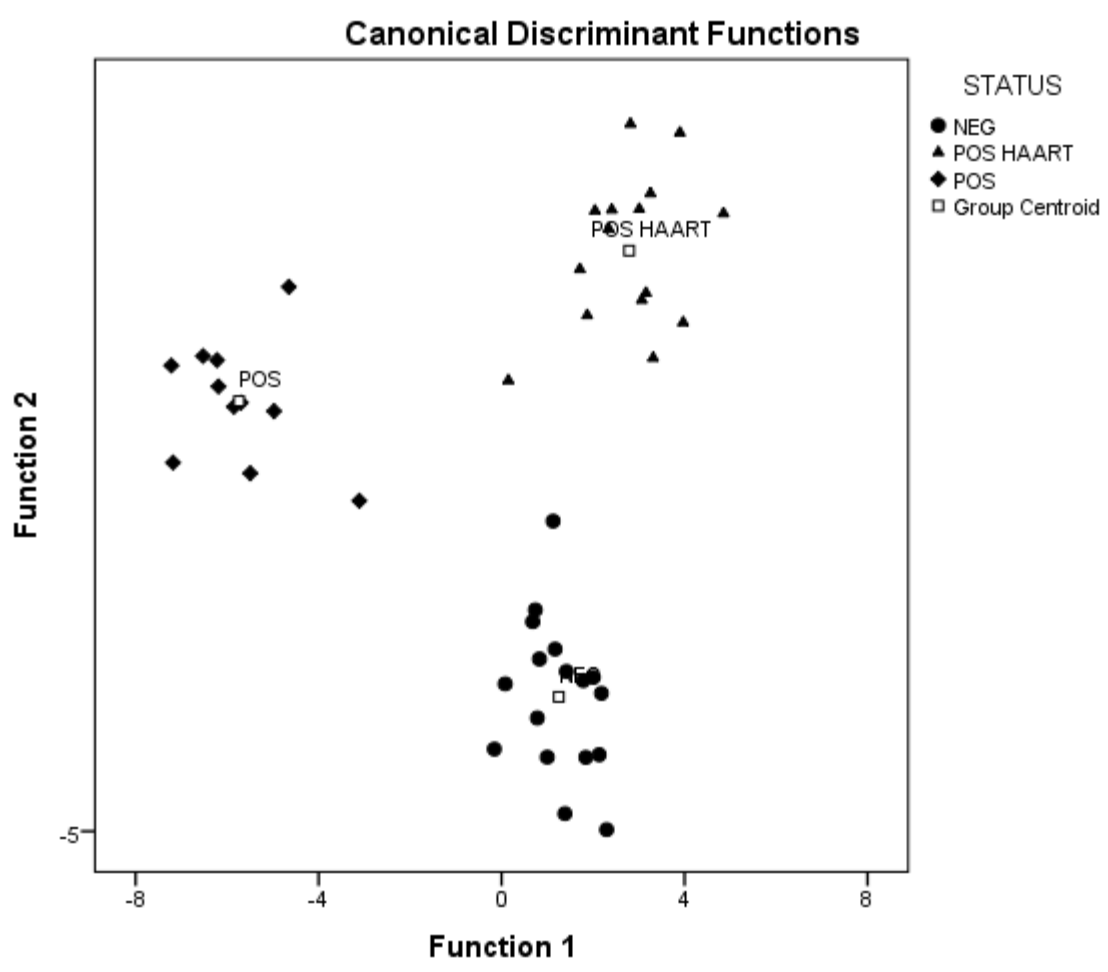

Figure S1 Principal component analysis (PCA) scores plot of HIV negative, HIV+ and HIV+HAART+ groups that were detected using UPLC-MS. The three experimental groups separated from each other, indicative of clear differentiation among them. The HIV+ group differentiated from the HIV negative and treated patients along the first discriminant while the HIV+ and treatment-experienced patients differentiated from HIV negative samples along the second discriminant. 

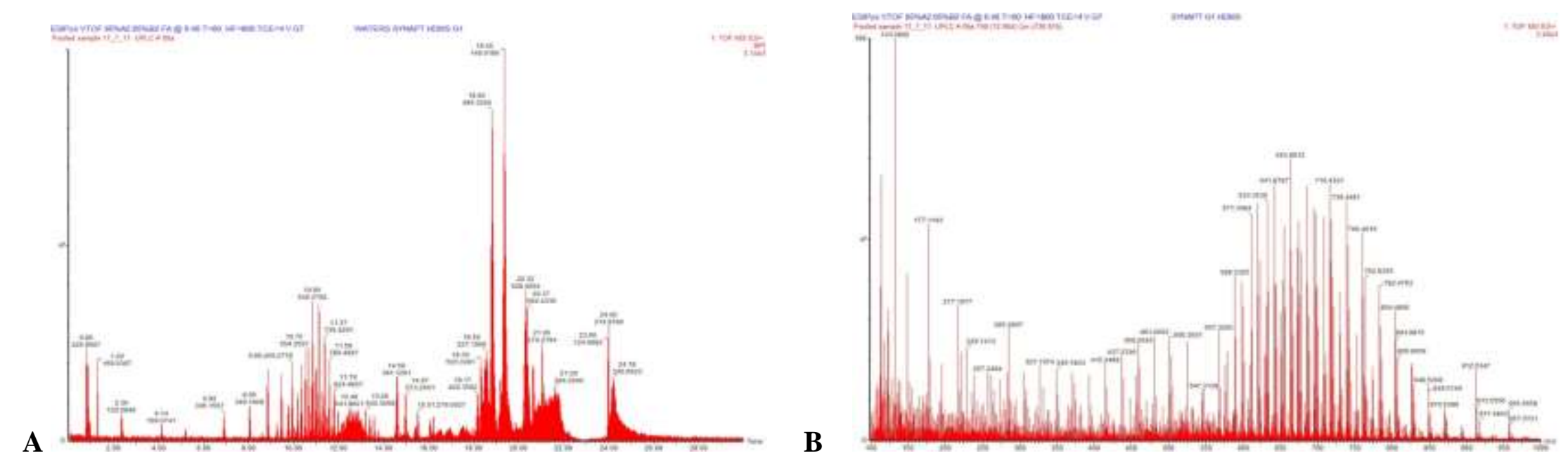

Figure S2: ESI positive BPI chromatogram (A) of pooled HIV sera after a multi-step solvent extraction protocol. In B, the presence of plasticizers and phospholipids are visible. The large amount of chromatographic peaks that originated from plasticizers made detecting and selecting metabolomics-related compounds very difficult. This is not surprising as these molecules are known too mask metabolites and suppress ionization of target compounds. Using the Ostro $^{\mathrm{TM}}$ plates eliminated both classes of compounds resulting in improved chromatography and mass spectral quality (shown in Figure 2 of the main manuscript). 


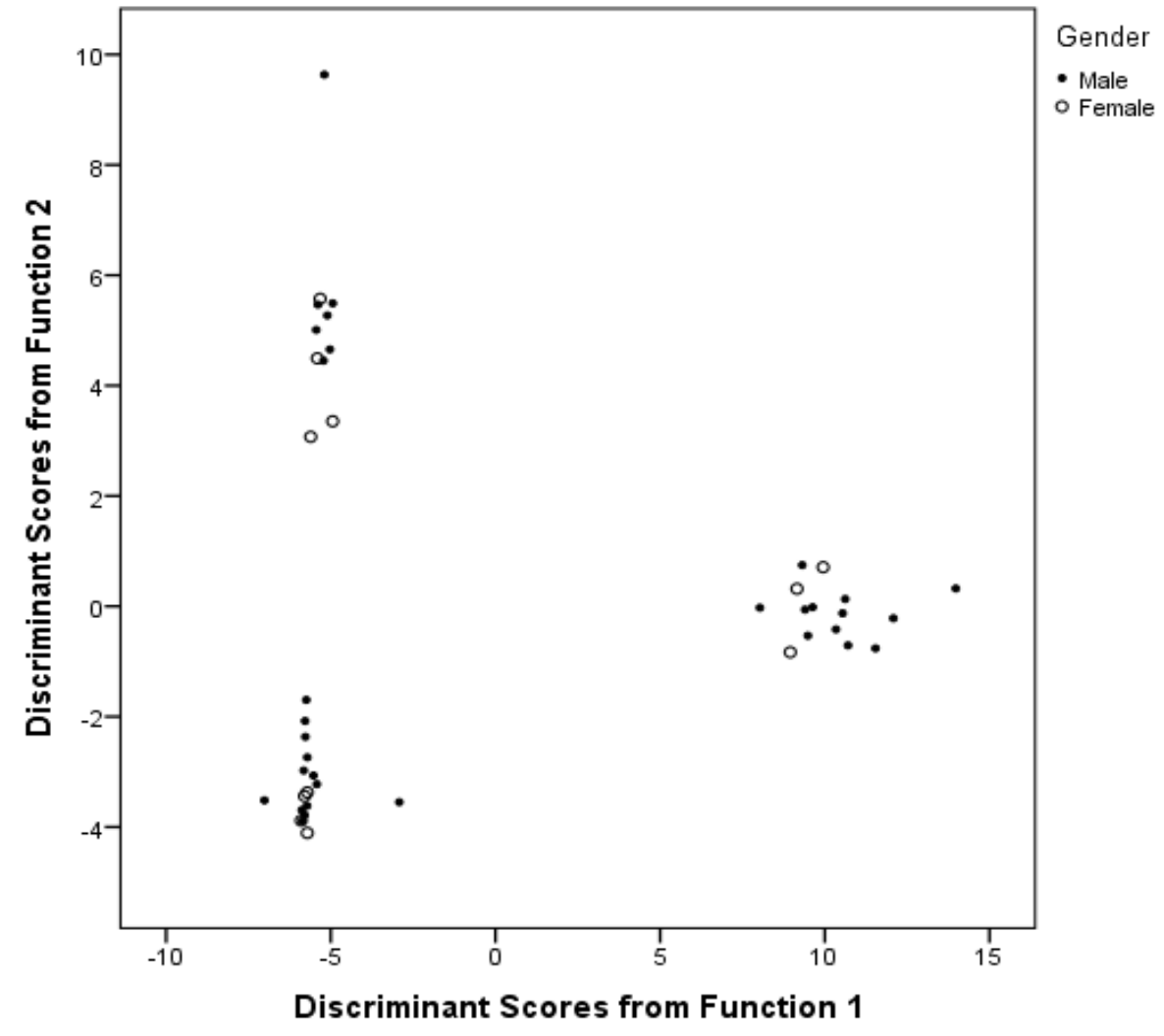

Figure S3. LDA scatter plot of HIV negative, HIV+ and HIV+HAART+ groups with the inclusion of gender as a variable. The scatter plot shows no clear separation between the genders. The means of the groups were not significant. This failure to cluster according to gender suggests that the separation of the groups is mainly as a result of HIV infection and/or treatment and not due to confounders like gender. Similar to the "gender-LDA" plot, age when entered as a variable did not play a significant role in the results either. 